\title{
Remote sensing of sea ice: advances during the DAMOCLES project
}

\author{
G. Heygster ${ }^{1}$, V. Alexandrov ${ }^{2}$, G. Dybkjær ${ }^{4}$, W. von Hoyningen-Huene ${ }^{1}$, F. Girard-Ardhuin ${ }^{3}$, I. L. Katsev ${ }^{5}$, \\ A. Kokhanovsky ${ }^{1}$, T. Lavergne ${ }^{6}$, A. V. Malinka ${ }^{5}$, C. Melsheimer ${ }^{1}$, L. Toudal Pedersen ${ }^{4}$, A. S. Prikhach ${ }^{5}$, R. Saldo ${ }^{7}$, \\ R. Tonboe ${ }^{4}$, H. Wiebe ${ }^{1}$, and E. P. Zege ${ }^{5}$ \\ ${ }^{1}$ Institute of Environmental Physics, University of Bremen (UB), Germany \\ ${ }^{2}$ Nansen International Environmental and Remote Sensing Centre (NIERSC), St. Petersburg, Russia and Nansen \\ Environmental and Remote Sensing Centre, Bergen, Norway \\ ${ }^{3}$ Institut Français de Recherche pour l'Exploitation de la Mer (IFREMER), Plouzané, France \\ ${ }^{4}$ Danish Meteorological Institute (DMI), Denmark \\ ${ }^{5}$ B.I. Stepanov Institute of Physics of the National Academy of Sciences of Belarus (IP-NASB), Minsk, Belarusian \\ ${ }^{6}$ Norwegian Meteorological Institute (met.no), Oslo, Norway \\ ${ }^{7}$ Danish National Space Center (DNSC), Copenhagen, Denmark
}

Correspondence to: G. Heygster (heygster@uni-bremen.de)

Received: 29 November 2011 - Published in The Cryosphere Discuss.: 3 January 2012

Revised: 22 August 2012 - Accepted: 13 October 2012 - Published: 3 December 2012

\begin{abstract}
In the Arctic, global warming is particularly pronounced so that we need to monitor its development continuously. On the other hand, the vast and hostile conditions make in situ observation difficult, so that available satellite observations should be exploited in the best possible way to extract geophysical information. Here, we give a résumé of the sea ice remote sensing efforts of the European Union's (EU) project DAMOCLES (Developing Arctic Modeling and Observing Capabilities for Long-term Environmental Studies). In order to better understand the seasonal variation of the microwave emission of sea ice observed from space, the monthly variations of the microwave emissivity of first-year and multi-year sea ice have been derived for the frequencies of the microwave imagers like AMSR-E (Advanced Microwave Scanning Radiometer on EOS) and sounding frequencies of AMSU (Advanced Microwave Sounding Unit), and have been used to develop an optimal estimation method to retrieve sea ice and atmospheric parameters simultaneously. In addition, a sea ice microwave emissivity model has been used together with a thermodynamic model to establish relations between the emissivities from $6 \mathrm{GHz}$ to $50 \mathrm{GHz}$. At the latter frequency, the emissivity is needed for assimilation into atmospheric circulation models, but is more difficult to observe directly. The size of the snow grains on top of the sea ice influences both its albedo and the microwave emission. A method to determine the effective size of the snow grains
\end{abstract}

from observations in the visible range (MODIS) is developed and demonstrated in an application on the Ross ice shelf. The bidirectional reflectivity distribution function (BRDF) of snow, which is an essential input parameter to the retrieval, has been measured in situ on Svalbard during the DAMOCLES campaign, and a BRDF model assuming aspherical particles is developed. Sea ice drift and deformation is derived from satellite observations with the scatterometer ASCAT $(62.5 \mathrm{~km}$ grid spacing), with visible AVHRR observations $(20 \mathrm{~km})$, with the synthetic aperture radar sensor ASAR $(10 \mathrm{~km})$, and a multi-sensor product $(62.5 \mathrm{~km})$ with improved angular resolution (Continuous Maximum Cross Correlation, CMCC method) is presented. CMCC is also used to derive the sea ice deformation, important for formation of sea ice leads (diverging deformation) and pressure ridges (converging). The indirect determination of sea ice thickness from altimeter freeboard data requires knowledge of the ice density and snow load on sea ice. The relation between freeboard and ice thickness is investigated based on the airborne Sever expeditions conducted between 1928 and 1993. 


\section{Introduction}

Sea ice is an essential component of the climate system at high latitudes. It influences weather and climate on both regional and global scales. Sea ice is an efficient insulator that strongly reduces fluxes of heat and vapour between ocean and atmosphere, where even a few percent of open water or refrozen thin ice in the Arctic sea ice may increase the heat flux between ocean and atmosphere drastically and increase $2 \mathrm{~m}$ air temperatures by several degrees (Lüpkes et al., 2008). The combination of thinning Arctic sea ice and the positive albedo feedback mechanism, caused by relative low albedo of the open ocean, are considered the main reasons for the signal of global warming to be amplified in the Arctic (Serreze et al., 2009). Sea ice extent, concentration, drift and deformation are therefore important parameters for both coupled climate circulation models and for operational applications like numerical weather prediction. These characteristics must be monitored continuously. The goal of this review is to combine and bundle the progress of sea ice remote sensing capabilities achieved during the project DAMOCLES (Developing Arctic Modeling and Observing Capabilities for Long-term Environmental Studies) conducted from 2006 to 2010. DAMOCLES was one of the main European contributions to the International Polar Year.

For observing sea ice from space, passive microwave sensors have the advantages of not requiring sunlight (they observe thermal radiation) and can thus also collect measurements during the (polar) night, and are also widely independent of cloud cover. Moreover, their availability since 1972 makes passive microwave observations the longest of all satellite records available and allows for analyses on climate time scales. However, the amount of emitted radiation (radiance) is much higher and varies much more over sea ice than over open water, making it difficult to estimate areas covered by the main sea ice type (first-year ice or multi-year ice) and to determine atmospheric quantities from microwave observations over sea ice. The necessary step to improve this situation of better estimating the microwave emissivity at the microwave observing frequencies is presented in Sect. 2.1, together with an application to retrieve both surface and atmospheric parameters over sea ice. As an attempt to predict the sea ice emissivity from the meteorological history, Sect. 2.3 combines a sea ice emissivity model with a thermodynamic model, driven with ECMWF atmospheric model data (Tonboe, 2010).

Knowledge of the sea ice temperature is required to determine the energy flux between ocean and atmosphere. It is relevant when retrieving the microwave emissivity (see above), and is needed to determine the atmospheric temperature profile from data of temperature sounders like AMSU-A (part of AMSU). In thermodynamic equilibrium, the vertical temperature profile within the sea ice and snow pack is characterized by the snow surface temperature and the snow/ice interface temperature. Section 3 investigates the relation between these two quantities and the brightness temperatures, together with a study investigating which microwave frequencies are best suited as proxies for assimilation in atmospheric circulation models.

Snow on top of the sea ice is relatively slight in mass, but crucial for climate change studies because not only the area covered by snow and ice is reduced with time (Seidel and Martinec, 2004), but also the snow strongly influences the albedo of the sea ice, and thus the local radiative balance that plays an essential role for the albedo feedback process. The albedo of snow does not have a constant value, but depends on the grain size (with smaller grains having higher albedo) and the amount of pollution like soot (e.g. in Eurasia, Hansen and Nazarenko, 2004) and in fewer cases dust, which both lower the albedo significantly. Other factors contributing to snow and sea ice albedo are the solar zenith angle, cloud cover, surface tilt and even air humidity (Pirazzini, 2004). DAMOCLES has contributed to our remote sensing capabilities for the snow grain size (Sect. 4.1), which is based on the knowledge of the reflectance function (Sect. 4.2), and to the retrieval of the albedo itself (Sect. 4.3).

Sea ice drift and deformation are dynamic parameters influencing the open water fraction and ice thickness distribution and hence the energy and mass balance of the Arctic sea ice. Section 5 presents progress, in the detection of sea ice drift and deformation derived from the METOP instruments scatterometer ASCAT, the optical radiometer AVHRR, from ASCAT (Advanced Synthetic Aperture Radar) on ENVISAT and from passive microwave radiometers on Aqua and DMSP satellites.

Information on sea ice thickness is needed to determine the ice volume, to compute the ice mass exchanges with the ocean, to validate numerical models of the ocean circulation as well as to plan ship and offshore operations in the ice. In the last $10 \mathrm{yr}$, radar altimeter data from ERS and ENVISAT have been used to determine the inter-annual changes in sea ice thickness through direct measurements of sea ice freeboard. The contribution of DAMOCLES, presented in Sect. 6, was an investigation on the relation between freeboard and ice thickness based on the airborne Sever expeditions conducted between 1928 and 1993.

\section{Sea ice microwave emissivity}

\subsection{Emissivity determination}

The satellite observed radiance, called brightness temperature $T_{\mathrm{b}}=T_{\mathrm{em}} \times \varepsilon$, is the product of the physical temperature $T_{\mathrm{em}}$ of the isothermal emitting layer and the emissivity $\varepsilon$, a material parameter. Over open ocean, microwave observations have been used for many decades to determine a wide range of surface and atmospheric parameters such as surface temperature, wind speed, atmospheric total water vapour, liquid water and precipitation. Over sea ice, we so far only have 
been able to retrieve concentrations (percentage of surface cover) of total ice (Andersen et al., 2007) and multi-year ice (ice having survived at least one summer melt season) (Cavalieri et al., 1984; now used with tie points from Comiso et al., 1997). The reason why we can extract so much less geophysical information from microwave observations over sea ice is the high and highly varying sea ice emissivity, making it difficult to determine the much smaller atmospheric component of the received radiation. In the frequency range from 6 to $90 \mathrm{GHz}$, the emissivity of open water increases from about 0.4 to 0.6 (with the vertically polarized emissivity about 0.25 higher than the horizontal one), whereas that of first-year ice varies between 0.85 and 0.95 , and that of multi-year ice between 0.9 and 0.55 (Spreen et al., 2008). However, the uncertainty in the emissivity of open water, influenced by temperature and wind speed, increases in the same frequency range from 0.2 to $2.1 \mathrm{~K}$ (Wentz, 1983), but that of sea ice varies according to ice type and frequency between $6 \mathrm{~K}$ (first-year ice at $6 \mathrm{GHz}$ ) and $16 \mathrm{~K}$ (multi-year ice at $37 \mathrm{GHz}$ ) (Eppler et al., 1992). Moreover, the microwave radiation emanates, compared to water, from much deeper layers of snow and ice where the meteorological history is frozen in the microphysical parameters, resulting in a much more complex relationship between physical properties of the snow/ice complex and the microwave radiances. As a consequence, reliable emissivity forward models, while existing for open water (e.g. Wentz, 1983), remain a challenge for the case of sea ice (Tonboe et al., 2006).

As an additional difficulty, in winter the high vertical temperature gradient within the sea ice from about $-30^{\circ} \mathrm{C}$ at the surface to $-1.8^{\circ} \mathrm{C}$ at the bottom complicates the determination of the temperature of the emitting layer at the different observing frequencies, which span the range from 6 to $183 \mathrm{GHz}$ and have different penetration depths. In order to characterize the temperature of an emitting layer that is not isothermal, but has a temperature gradient by a single scalar instead by a temperature profile, the concept of effective temperature is used. It is the temperature of a layer identical to the emitting layer, except being of homogeneous temperature, and emitting the same radiation as the layer with the temperature profile. This concept will be used in the next section on emissivity modelling.

Within DAMOCLES, the annual cycle of the emissivities of first-year and multi-year sea ice, the two most prominent ice types, were determined at all microwave observing frequencies of the sensors Advanced Microwave Sounding Unit (AMSU, consisting of the temperature sounding part AMSU-A at lower frequencies and the humidity sounding part AMSU-B at higher frequencies) for the year 2005 (Matthew et al., 2008) and Advanced Microwave Scanning Radiometer on EOS (AMSR-E) (Matthew et al., 2009). The horizontal resolutions of AMSU-A and B are $48 \mathrm{~km}$ and $16 \mathrm{~km}$ at nadir, where each 3 observations of AMSU-B are combined to correspond to one AMSU-A footprint. The res- olution of AMSR-E varies with frequency $(6.9 \ldots .89 \mathrm{GHz})$ between $43 \times 75 \mathrm{~km}$ and $3.5 \times 5.9 \mathrm{~km}$.

In both studies, the emissivity is retrieved over two Arctic regions, one covered by first-year ice $\left(76.5-78^{\circ} \mathrm{N}, 77-\right.$ $\left.79^{\circ} \mathrm{E}\right)$ in the Kara Sea and one covered by multi-year ice $\left(84-85.5^{\circ} \mathrm{N}, 31.5-36^{\circ} \mathrm{W}\right)$ north of Greenland. Knowledge about the surface temperature and atmospheric temperature and humidity profiles is provided from ECMWF ERA-40 reanalysis data available every $6 \mathrm{~h}$ in a grid of about $120 \mathrm{~km}$ resolution and with 60 vertical levels. Vertical temperature profile within the snow and sea ice pack are taken from the Heat Budget of the Arctic Ocean (SHEBA) observations in 1997 and 1998 (Ulbay et al., 2002) and penetration depth data from Haggerty and Curry (2001) are used to estimate the temperature of the emitting layer, using a linear regression. The discrepancy in time and space between satellite and in situ observations may introduce an error in the analysis, especially in view of a climatological change, but this was the best combination of data available at the time of the study. The emissivity $\varepsilon(v, \theta)$ at frequency $v$ and incidence angle $\vartheta$ is retrieved as the ratio $\left(T_{\mathrm{b}}(\nu, \theta)-T_{\mathrm{b}, 0}\right) /\left(T_{\mathrm{b}, 1}-T_{\mathrm{b}, 0}\right)$ where $T_{\mathrm{b}}(\nu, \theta)$ is the observed brightness temperature, and $T_{\mathrm{b}, 0}$ and $T_{\mathrm{b}, 1}$ are simulated brightness temperatures determined from known atmospheric profiles (Matthew et al., 2009).

Here we present as examples the monthly averaged results for first-year ice (Fig. 1) and multi-year ice (Fig. 2) for the AMSR-E frequencies ranging from 7 to $89 \mathrm{GHz}$. During the winter months, the surface emissivity and the concentrations of first-year ice shown also in Fig. 1 are near unity and the difference between horizontally and vertically polarized emissivity is low. During the months of June, July, and October, the satellite footprints may contain both ice and open water, leading to high variability (error bars) of the determined average emissivity. During August and September, the ice has completely melted and the emissivity of open water is observed. The monthly variation of multi-year ice (Fig. 2) remains nearly constant for all months except the summer months from May to September when the higher emissivity values are observed, with a maximum of 0.95 at $7 \mathrm{GHz}$ in June. The retrieved emissivities agree well with those of AMSU in the sense that for similar frequencies similar emissivities are found. As the polarization of the AMSU measurements varies with incidence angle, for such a comparison first the polarizations of the AMSR-E observations (horizontal and vertical) need to be converted to those of the AMSU observations at the AMSR-E incidence angle of $50^{\circ}$ (Matthew et al., 2009). For the first time, also the correlations between the emissivities at different frequencies and polarizations of AMSR-E have been determined (Mathew et al., 2009). The covariances, which are easily derived from the correlations, are required when assimilating the brightness temperatures into atmospheric and ocean circulation models.

As an application, the method was transferred to data of the atmospheric temperature sounder AMSU-A within the 
operational processing chain of the Norwegian Meteorolgoical Institute (Schyberg and Tveter, 2009, 2010).

Another important application of the emissivities is the retrieval of atmospheric parameters over sea ice, similarly as has been done over open ocean from passive microwave sensors for more than three decades. The idea is to model the radiances of the AMSR-E channels with a forward model that takes surface and atmospheric parameters as input, and then use an inverse method to retrieve these parameters (state variables) from the measured AMSR-E radiances. The state variables here are surface wind speed, total column water vapour (TWV), cloud liquid water path (CLW), sea surface temperature, ice surface effective temperature, sea ice concentration, and multi-year ice fraction. Note that the ice surface temperature is in fact the effective temperature of the emitting layer of the snow/ice complex, as introduced and described in the previous section.

The forward model is based on the one by Wentz and Meissner (2000) that simulates AMSR-E radiances over open water given wind speed, TWV, CLW, and surface temperature. We have modified this forward model to allow partial or full ice cover of the sea. This in turn requires knowledge of the sea ice emissivity of first-year ice and multi-year ice which is taken from the method mentioned above.

The inverse method, the "optimal estimation method" (Rodgers, 2000), requires a priori data and covariances for all state variables. The a priori data for the ice concentration are directly determined from the AMSR-E brightness temperatures (using the NASA Team algorithm), and the a priori surface temperatures are derived from the AMSR-E brightness temperatures, the ice concentration and the sea ice emissivities using the iterative method of the bootstrap algorithm as described by Comiso et al. (2003). The remaining a priori data are taken from meteorological analysis data (ECMWF). The solution has to be found by an iteration scheme (Newton method), and comprises not just the retrieved state variables, but also includes the a posteriori covariance matrix that contains the standard deviations (the uncertainties) of the retrieved variables and their mutual correlations.

The retrieval produces fields (swath by swath) of the state variables. The entire Arctic can be covered daily. However, mainly in areas of multi-year ice, the retrieval shows slow convergence - the most probable reason being that the emissivities of multi-year ice are not well enough represented in the forward model, as they are based on emissivity values retrieved for a certain area $\left(85-85.5^{\circ} \mathrm{N}, 31.5-36^{\circ} \mathrm{W}\right.$, see above).

\subsection{Emissivity modelling; combination with thermodynamic model}

It has been demonstrated that the seasonal variability of thermal microwave emission can be simulated using a combination of thermodynamic model and emission modelling. Combined thermodynamic and emissivity models generate long snow/sea ice/microwave time series that can be used for statistical analysis of radiometer sea ice data sensitivities (Mätzler et al., 2006). The purpose is not necessarily to reproduce a particular situation in time and space but rather to provide a realistic characterisation of the daily to seasonal variability.

In DAMOCLES the microwave emission processes from sea ice have been simulated using the combination of a one dimensional thermodynamic sea ice model and a microwave emission model (Tonboe, 2010; Tonboe et al., 2011). The emission model is the sea ice version of the Microwave Emission Model for Layered Snow-packs (MEMLS) (Wiesmann and Mätzler, 1999; Mätzler et al., 2006) It uses the theoretical improved Born approximation for estimating scattering, which validates for a wider range of frequencies and scatterer sizes than the empirical formulations (Mätzler and Wiesmann, 1999). Using the improved Born approximation, the shape of the scatters is important for the scattering magnitude (Mätzler, 1998). We assume spherical scatters in snow when the correlation length, a measure of grain size, is less than $0.2 \mathrm{~mm}$ and the scatters are formed as cups when greater than $0.2 \mathrm{~mm}$ to resemble depth hoar crystals. The sea ice version of MEMLS includes models for the sea ice dielectric properties while using the same principles for radiative transfer as the snow model. Again the scattering within sea ice layers beneath the snow is estimated using the improved Born approximation. The scattering in multi-year ice is assumed from small air bubbles within the ice. The emission model is used to simulate the sea ice Tb's and emissivity where the subscript $\mathrm{v}$ or $\mathrm{h}$ and number denote the polarization at oblique incidence angles and the frequency in $\mathrm{GHz}$, respectively, e.g. $e_{\mathrm{v} 89}$ for the emissivity at $89 \mathrm{GHz}$ and vertical polarization. All simulations are at $50^{\circ}$ incidence angle similar to SSMIS and other conically scanning radiometers.

The thermodynamic model has the following prognostic parameters for each layer: thermometric temperature, density, thickness, snow grain size and type, ice salinity and snow liquid water content. Snow layering is very important for the microwave signatures; therefore, it treats snow layers related to individual snow precipitation events. For sea ice it has a growth rate dependent salinity profile. The sea ice salinity is a function of growth rate and water salinity (32 psu) (Nagawo and Sinha, 1981).

Climatology indicates that there is snow on multi-year ice at the end of summer melt in September (Warren et al., 1999). Therefore, the multi-year ice simulations are initiated on 1 September with an isothermal $2.5 \mathrm{~m}$ ice floe with $5-\mathrm{cm}-$ old snow layer on top. The multi-year ice gradually grows at the six positions from $2.5 \mathrm{~m}$ to between 3.0 and $3.4 \mathrm{~m}$ in spring and snow depths during winter ranging between 0.2 and $0.5 \mathrm{~m}$. The mean snow depth in this data set is $0.26 \mathrm{~m}$ and the mean ice thickness is $2.8 \mathrm{~m}$. The snow/ice interface temperature is near $270 \mathrm{~K}$ in September and May and down to $230 \mathrm{~K}$ in March. The simulations are confined to these relatively cold conditions. The melt processes during 

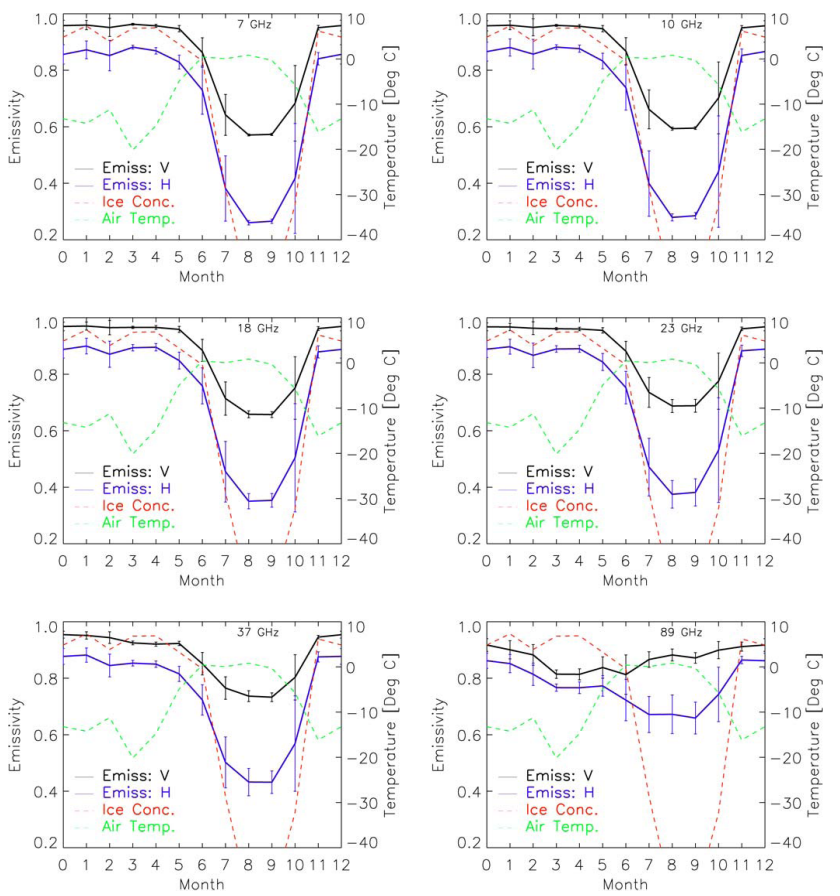

Fig. 1. Seasonal variation of emissivities of first-year ice at AMSRE frequencies, (black) vertical and (blue) horizontal polarizations. (Top left) 7, 10, 18, 23, 37 and (bottom right) $89 \mathrm{GHz}$. Red dashed line: ice concentration; green dashed line: air temperature. Months 0 and 12 are the same from Matthew et al. (2009).

the summer season are complicated and not sufficiently described by the thermodynamic model. Summer melt is therefore not included in this study. The thermodynamic model is further described in Tonboe (2010) and Tonboe et al. (2011).

The thermodynamic model is fed with ECMWF ERA 40 data input at $6 \mathrm{~h}$ intervals. The parameters used as input to the thermodynamic model are the surface air pressure, the $2 \mathrm{~m}$ air temperature, the $10 \mathrm{~m}$ wind speed, the incoming short-wave solar radiation, the incoming long-wave radiation, the dewpoint temperature and precipitation. In return the thermodynamic model produces detailed snow and ice profiles which are input to the emission model at each time-step. The input to the emission model is snow and ice density, snow grain size and scatter size in ice, temperature, salinity and snow type. The layer thickness in the snow-pack is determined at each precipitation event and the subsequent metamorphosis.

Emissivity at 18,36 and $89 \mathrm{GHz}$, its temporal variability, the gradient ratio at 18 and $36 \mathrm{GHz}\left(\mathrm{GR}_{18 / 36}=\left(T_{36 \mathrm{v}}-\right.\right.$ $\left.\left.T_{18 \mathrm{v}}\right) /\left(T_{36 \mathrm{v}}+T_{18 \mathrm{v}}\right)\right)$, and the polarisation ratio at $18 \mathrm{GHz}$ $\left(\mathrm{PR}_{18}=\left(T_{18 \mathrm{v}}-T_{18 \mathrm{~h}}\right) /\left(T_{18 \mathrm{v}}+T_{18 \mathrm{~h}}\right)\right)$ are comparable to typical signatures derived from satellite measurements (Tonboe, 2010).

The correlation between each of the multi-year ice parameters - brightness temperature $\left(T_{\mathrm{v}}\right)$, emissivity $\left(e_{\mathrm{v}}\right)$ and effective temperature ( $T_{\text {eff }}$, see explanation in Sect. 2.1) - at neighbouring frequencies 18,36 and $50 \mathrm{GHz}$ is high $(r \geq 0.94)$.
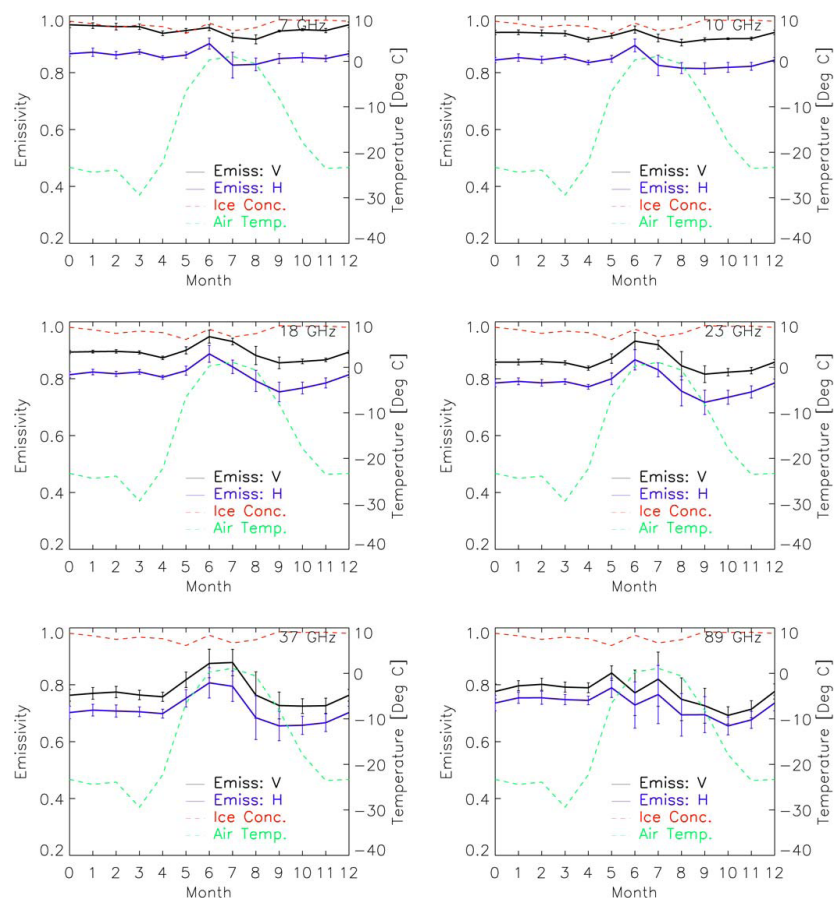

Fig. 2. Seasonal variation of emissivities of multi-year ice at AMSR-E frequencies [(black) vertical and (blue) horizontal polarizations]. (Top left) 7, 10, 18, 23, 37 and (bottom right) $89 \mathrm{GHz}$. Red dashed line: ice concentration; green dashed line: air temperature. Months 0 and 12 are the same from Mathew et al. (2009).

The correlation between each of the 18 and $36 \mathrm{GHz}$ multiyear ice parameters $e_{\mathrm{v}}, T_{\text {eff }}$ and $T_{\mathrm{v}}$ is equally good for physical temperatures near the melting point and low temperatures during winter. The melting season is not included and the correlations are referring to snow ice interface temperatures less than about $270 \mathrm{~K}$ and above $240 \mathrm{~K}$ (Tonboe et al., 2011). These lower frequencies $(18-50 \mathrm{GHz})$ penetrate into the multi-year ice, while the penetration of the $89 \mathrm{GHz}$ reaches only to the snow ice interface. The high frequency channels at 150 and $183 \mathrm{GHz}$ are penetrating only the snow surface and the correlation between these is also high $(r=$ 0.99). However, the emissivity of multi-year ice at $89 \mathrm{GHz}$, $e_{\mathrm{v} 89}$, in between the high and low frequency channels is relatively poorly correlated to its frequency neighbours, i.e. the correlation coefficient between $89 \mathrm{GHz}$ and $50 \mathrm{GHz}$ is 0.83 and 0.87 to $150 \mathrm{GHz}$. For cases with little extinction in the snow, the microwave penetration at $89 \mathrm{GHz}$ is to the snow/ice interface. For cases with deeper snow or depth hoar giving stronger extinction in the snow, the $89 \mathrm{GHz}$ emission is primarily from the snow. The shift between the two emission regimes can strongly influence $T_{\mathrm{v} 89}$ and its correlation to neighbouring frequencies. Figure 3 shows the emissivity at 18,36 and $89 \mathrm{GHz}$ and vertical polarisation vs. the emissivity at $50 \mathrm{GHz}$. 
The emissivity is affected by volume scattering processes in the snow cover and also absorption in the upper ice. The $\mathrm{GR}_{18 / 36}$, which is a measurable proxy for scattering, is further related to the emissivity of multi-year ice $e_{\mathrm{v} 50}$ at $50 \mathrm{GHz}$. The linear relationship between these two simulated parameters seems to be robust over the wide range of temperatures and snow depths covered by the cases of Fig. 3. However, the relationships of $T_{\text {eff }}$ to measurable parameters such as air or surface temperature show less correlation because of the steep temperature gradient near the surface and the penetration depth variability. Nevertheless, $T_{\text {eff }}$ is highly correlated with that of neighbouring channels. The simulated relationship between $\mathrm{GR}_{18 / 36}$ and $e_{\mathrm{v} 50}$ suggests that it may be possible to estimate the microwave emissivity at the atmospheric sounding frequencies $(\sim 50 \mathrm{GHz})$ from satellite measurements at lower frequencies seasonally across the Arctic Ocean with microwave instruments such as SSMIS, as it is done over open water. The emissivity of the sounding frequencies cannot be detected directly from observations in these channels because they are dominated by the atmospheric signal component, which in addition is difficult to separate from the surface contribution.

Test runs with the regional numerical weather prediction model HIRLAM (High Resolution Limited Area Model) where satellite microwave radiometer data from sea ice covered regions were assimilated indicated that atmospheric temperature sounding of the troposphere over sea ice, which is not practiced in current numerical weather prediction models, is feasible (Heygster et al., 2009). The test showed that the assimilation of AMSU-A near $50 \mathrm{GHz}$ temperature sounding data over sea ice improved model skill on common variables such as surface temperature, wind and air pressure. These promising test results are the motivation for the new EUMETSAT Ocean and Sea Ice Satellite Application Facility (OSI SAF) sea ice emissivity model.

The OSISAF emissivity model is based on simulated correlations between the surface brightness temperature at 18 and $36 \mathrm{GHz}$ and at $50 \mathrm{GHz}$. The model coefficients are tuned with simulated data from a combined thermodynamic and emission model in DAMOCLES. The intention with the model is to provide a first guess sea ice surface emissivity estimate for tropospheric temperature sounding in numerical weather prediction models assimilating both AMSU and Special Sensor Microwave Imager/Sounder (SSMI/S) data (Tonboe and Schyberg, 2011).

\section{Snow and sea ice temperatures}

The snow surface temperature is among the most important variables in the surface energy balance equation and it strongly interacts with the atmospheric boundary layer structure, the turbulent heat exchange and the ice growth rate.

The snow surface on thick multi-year sea ice in winter is on average colder than the air because of the negative radia-

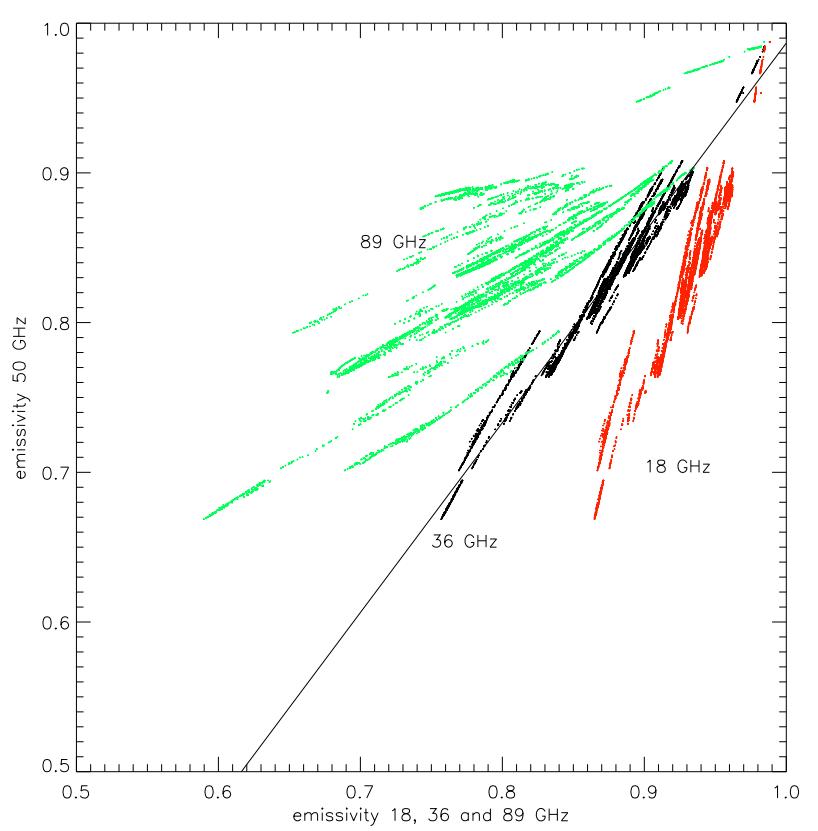

Fig. 3. The simulated 18,36 and $89 \mathrm{GHz}$ emissivity at vertical polarisation of multi-year ice vs. the $50 \mathrm{GHz}$ emissivity. The $18 \mathrm{GHz}$ vs. the $50 \mathrm{GHz}$ emissivity is shown in red, the $36 \mathrm{GHz}$ vs. the $50 \mathrm{GHz}$ in black, and the $89 \mathrm{GHz}$ vs. the $50 \mathrm{GHz}$ in green. The line is fitted to the $36 \mathrm{GHz}$ vs. $50 \mathrm{GHz}$ cluster: $e_{\mathrm{v} 50}=1.268 e_{\mathrm{v} 36}-0.28$.

tion balance (Maykut, 1986). Beneath the snow surface there is a strong temperature gradient with increasing temperatures towards the ice-water interface temperature at the freezing point around $-1.8^{\circ} \mathrm{C}$. With the thermodynamic model presented in Tonboe (2010) and in Tonboe et al. (2011), the sea ice surface temperature and the thermal microwave brightness temperature were simulated using a combination of thermodynamic and microwave emission models (Tonboe et al., 2011).

The simulations indicate that the physical snow/ice interface temperature or alternatively the $6 \mathrm{GHz}$ effective temperature have a good correlation with the effective temperature at the temperature sounding channels near $50 \mathrm{GHz}$. The physical snow/ice interface temperature is related to the brightness temperature at $6 \mathrm{GHz}$ vertical polarisation as expected. The simulations reveal that the $6 \mathrm{GHz}$ brightness temperature can be related to the snow/ice interface temperature correcting for the temperature dependent penetration depth in saline ice. The penetration is deeper at colder temperatures and shallower at warmer temperatures. This means the $6 \mathrm{GHz}$ $T_{\text {eff }}$ is relatively warmer than the snow/ice interface temperature at colder physical temperatures because of deeper penetration, in line with the findings of Ulaby et al. (1986) that the penetration depth increases with decreasing temperatures

Nevertheless, it may be possible to derive the snow/ice interface temperature from the $6 \mathrm{GHz}$ brightness temperature. The snow/ice interface temperature estimate may be more 

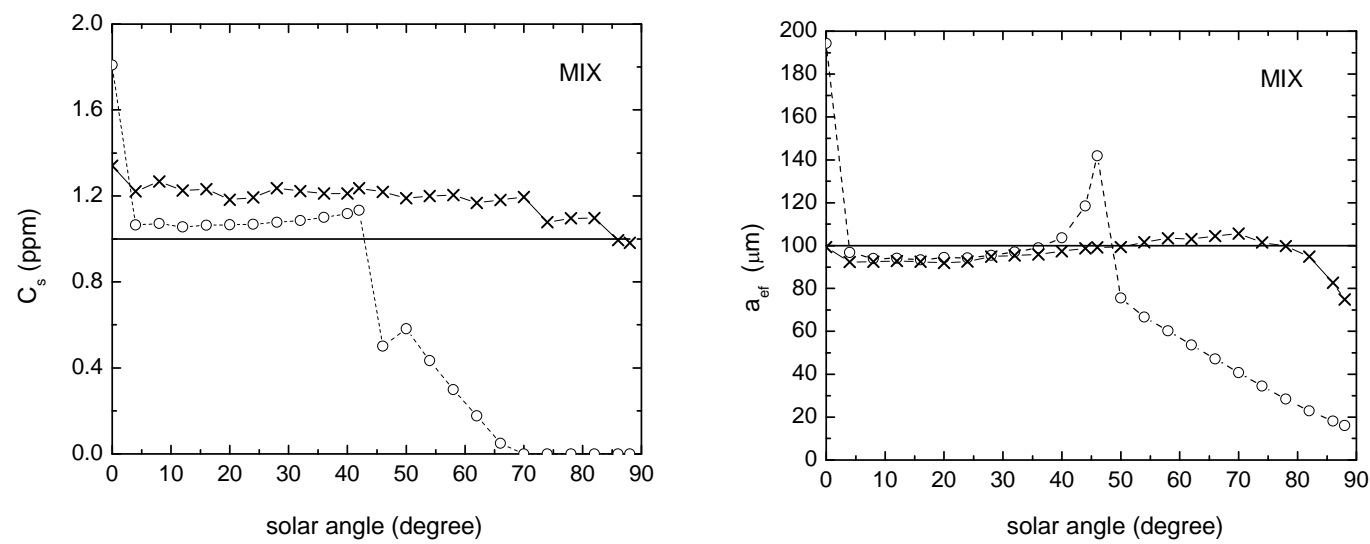

Fig. 4. Retrieval of effective snow grain size and soot concentration by two methods: SGSP $(-\times)$ and LUT-Mie $(-\bigcirc)$; Nadir observation. Horizontal lines mark true values.

easily used in physical modelling than the effective temperature. Hydrodynamic ocean and sea ice models with advanced sea ice modules simulate the snow surface and snow/ice temperatures explicitly.

The simulations with the combined thermodynamic and emission model show that the $6 \mathrm{GHz}$ brightness or effective temperature estimates (Hwang and Barber, 2008) or the snow/ice interface temperature is a closer proxy for the effective temperature near $50 \mathrm{GHz}$ than the snow surface temperature. This is compatible with the value of about $6 \mathrm{~cm}$ penetration depth for multi-year ice, as interpolated in Mathew et al. (2008) from Haggerty and Curry (2001).

The snow surface temperature can be measured with infrared radiometers and the effective temperature at $6 \mathrm{GHz}$ can be estimated using the $6 \mathrm{GHz}$ brightness temperature. Because of the large temperature gradient in the snow and the ice and the low heat conduction rate in snow, the snow surface temperature is relatively poorly correlated with both the snow/ice interface temperature and the effective temperatures between 6 and $89 \mathrm{GHz}$. However, the effective temperatures between $6 \mathrm{GHz}$ and $89 \mathrm{GHz}$ are highly correlated.

\section{Snow on sea ice}

\subsection{Retrieval of snow grain size}

Snow on top of the sea ice contributes to the processes of snow ice formation (due to refreezing of ocean flooding) and superimposed ice formation (via refreezing of meltwater or rain), and it influences the albedo of the sea ice, and thus the local radiative balance, which plays an essential role for the albedo feedback process and ice melting. The albedo of snow does not have a constant value, but depends on the grain size (snow with smaller grains has higher albedo) and the amount of pollution like soot and in fewer cases dust, which both lead to lower albedo. Satellite remote sensing is an important tool for snow cover monitoring, especially over difficult-to-access polar regions.

Within DAMOCLES, a new algorithm for retrieving the Snow Grain Size and Pollution (SGSP) for snow on sea ice and land ice from satellite data has been developed (Zege et al., 2008, 2011). This algorithm is based on the analytical solution for snow reflectance within the asymptotic radiative transfer theory (Zege et al., 1991). The unique feature of the SGSP algorithm is that the results depend only very weakly on the snow grain shape. The SGSP accounts for the Bidirectional Reflectance Distribution Function (BRDF) of the snow pack. It works at low Sun elevations, which are typical for polar regions. Because of the analytical nature of the basic equations used in the algorithm, the SGSP code is fast enough for near-real time applications to large-scale satellite data. The SGSP code includes the new atmospheric correction procedure that accounts for the real BRDF of the particular snow pack.

Note that developments of earlier methods for snow remote sensing (Han et al., 1999; Hori et al., 2001; Stamnes et al., 2007) were based on the model of snow as an ensemble of spherical ice particles. In these approaches, Mie code was used to calculate snow optical characteristics and some radiative transfer codes were deployed to calculate look-up tables (LUT-Mie technique). It seemed that the fact that snow grains in polar snow packs tend to become rounded during the metamorphism process made this concept more trustworthy. But the phase functions of these rounded grains (as of all other particles that are not ideal spheres) drastically differ from those for ideal ice spheres, particularly for the scattering angles in the range $60-170^{\circ}$ typical for satellite remote sensing, as with MODIS in polar region. This feature cannot be described with the Mie theory (Zege et al., 2011). Within DAMOCLES it was shown that these methods could provide grain size retrievals with errors below $40 \%$ only when zenith angles of the Sun are less than $40-50^{\circ}$ (Fig. 4, right). In polar regions, where the Sun position is generally low, 
the frequently used LUT-Mie technique and the disregard of the real snow BDRF (particularly the use of the Lambertian reflectance model) may lead to grain size errors of 40 to $250 \%$ in the retrieved values if the Sun zenith angle varies between 50 and $75^{\circ}$, whereas the SGSP retrieval does not exceed $10 \%$. This is illustrated in the computer simulations of Fig. 4. The comparatively fresh snow that is modelled as a mixture (MIX) of different ice crystals is considered here with grain effective size of $100 \mu \mathrm{m}$ and a soot load of $1 \mathrm{ppm}$.

These simulations were performed with the software tool SRS (Snow Remote Sensing), developed under DAMOCLES specifically to study the accuracy of various approaches and retrieval techniques for snow remote sensing. SRS simulates the bidirectional reflectance from a snow-atmosphere system at the atmosphere top and the signals in the spectral channels of optical satellite instruments. SRS includes the accurate and fast radiative transfer code RAY (Tynes et al., 2001), realistic and changeable atmosphere models with stratification of all components (aerosol, gases) and realistic models of stratified snow. The simulated signals in the spectral channels of MODIS were used for retrieval performed both with SGSP and Mie-LUT codes. The SGSP method provides reasonable accuracy at all possible solar angles, while the LUT-Mie retrieval technique fails when snow grains are not spherical at oblique solar angles. This conclusion is of great importance for snow satellite sensing in polar regions where the sun elevation is always low.

The SGSP includes newly developed iterative atmospheric correction procedure that allows for the real snow BDRF and provides a reasonable accuracy of the snow parameters retrieval even at the low sun positions typical for polar regions.

The SGSP algorithm has been extensively and successfully validated (Zege et al., 2011; Wiebe et al., 2012) using computer simulations with SRS code. Detailed comparison with field data obtained during campaigns carried out by Aoki et al. (2007), where the micro-physical snow grain size was measured using a lens and a ruler, was performed as well (Wiebe at al., 2012). The SGSP-retrieved snow grain size complies well with the in-situ measured snow grain size.

The SGSP code with the atmospheric correction procedure is operationally applied in the MODIS processing chain providing MODIS snow product for selected polar regions (see www.iup.uni-bremen.de/seaice/amsr/modis.html). Figure 5 shows an example of the operational retrieval of snow grain size on the Ross ice shelf. The large-scale variation of the snow grain size depicted in the figure might be cause by regionally varying meteorological influences like snow deposition, as explained in a local study by Wiebe et al. (2012) by comparison of a time series with observations from an automated weather station, and by temperatures reaching nearly melting during this season.

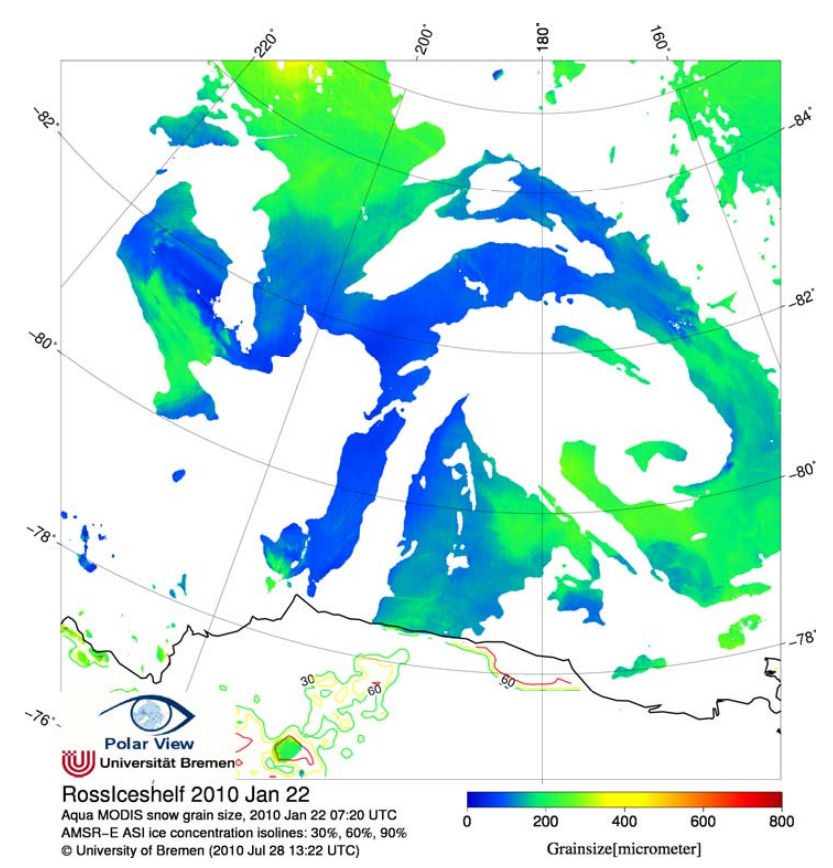

Fig. 5. Snow grain size retrieval example on the Ross ice shelf as provided in near real time.

\subsection{In situ measurements of snow reflectance}

For validation of any remote surface sensing observations from satellite, in situ observations are required. These are difficult to obtain in the high Arctic. The in situ component of the Damocles project has helped to fulfil these requirements with a campaign of 15 scientists, 2 weeks total duration at end of April 2007, to Longyearbyen, Svalbard, and to the schooner Tara drifting with the sea ice (Gascard et al., 2008).

The original plan had been to measure the snow reflectance with a Sun photometer CIMEL CE 318 at both places. However, it turned out that the sea ice surface near Tara drifting at the time of the campaign near $88^{\circ} \mathrm{N}$ was too rough, so that snow reflectance measurements were only taken in Longyearbyen. The observation site was the flat top of a $450 \mathrm{~m}$ high hill with few radomes for satellite communications at a distance of several hundreds of meters. The terrain was gently sloping towards $5^{\circ} \mathrm{W}$. Taking the reflectance measurements at Longyearbyen as a proxy for those at Tara may introduce two types of errors, namely by differences in roughness and salinity. We assume that the difference in roughness cancels out if considering footprint sizes at satellite sensors scales (about $1 \mathrm{~km}^{2}$ ). Also the difference in snow salinity should be small as at this season the snow cover was about 15 to $25 \mathrm{~cm}$. No indications of seawater flooding of the lower snow layers were found near Tara, and if, then it would have been hardly visible as the penetration depth of sunlight into the snow is clearly less. 


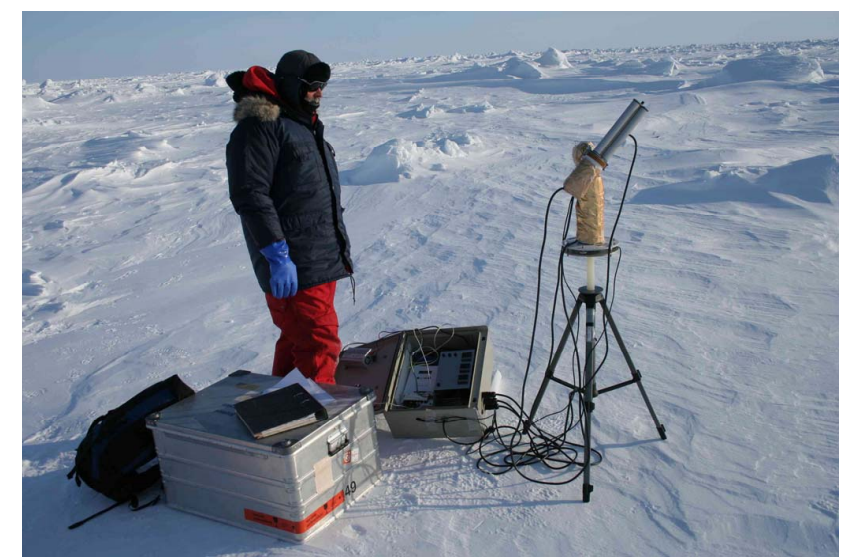

Fig. 6. The CIMEL Sun photometer CE 318 equipped with additional heating and thermal insulation (golden color) during sky observations on the Arctic sea ice near Tara at about $88^{\circ} \mathrm{N}$.

The Sun photometer CIMEL CE 318 had been equipped with two additional heatings and a thermal insulation (Fig. 6) in order to ensure reliable functioning of the electrical and mechanical drive and the electronics under Arctic conditions. The photometer is able to observe at 8 wavelengths, of which 6 were used here, namely 340, 440, 500, 670, 870 and $1020 \mathrm{~nm}$. The channels at $380 \mathrm{~nm}$ and $940 \mathrm{~nm}$, strongly influenced by calibration problems and water vapour, respectively, were not used. Three types of radiance measurements were performed, in the sky along the Sun principal plane and along Sun almucantars, i.e. circles parallel to the horizon at the Sun elevation. The surface reflectance in direction towards the Sun and perpendicular to it was also measured. While the sky measurement sequences are ready programmed in the photometer by the provider, the reflectance measurements were realized by an additional metal mirror placed under an angle of $45^{\circ}$ in front of the photometer, deflecting the incoming radiation by $90^{\circ}$ from the ground so that the pre-installed Sun principal plane observation program could also be used for the surface measurements. The opening angle of the photometer of $1.2^{\circ}$ leads at a height of the photometer head of $1.2 \mathrm{~m}$ above ground, to a footprint of the sensor on ground varying between 1.3 and $7.2 \mathrm{~mm}$ if the observing zenith angles varies from 10 to $80^{\circ}$.

The snow reflectance at view nadir angles 0 to $80^{\circ}$ was measured on 21 April. Figure 7 and Table 1 show the results from two wavelengths, 440 and $1040 \mathrm{~nm}$. At $440 \mathrm{~nm}$, the reflectance increases from about 0.9 to 1.6 with the view angle towards the Sun increasing from $0^{\circ}$ to $80^{\circ}$. In the perpendicular direction, the increase is much slower and reaches only up to about 1.0. In both directions, several curves have been taken. The observed variability of the reflectance can be explained with the small diameter of the footprint, so that different and independent spots are observed from one photometer run to the next. The reflectance at $1020 \mathrm{~nm}$ wavelength shows a similar behaviour, but starts at clearly lower
Table 1. Comparison of reflectances taken in situ at Longyearbyen (this paper), and from space by PARASOL over Greenland and Antarctica (Kokhanvosky and Breon, 2011).

\begin{tabular}{|c|c|c|c|c|c|c|}
\hline & \multicolumn{3}{|c|}{ Direction towards Sun } & \multicolumn{3}{|c|}{ Direction perpendicular to Sun } \\
\hline & $0^{\circ}$ & $60^{\circ}$ & $80^{\circ}$ & $0^{\circ}$ & $50^{\circ}$ & $80^{\circ}$ \\
\hline \multicolumn{7}{|c|}{$1020 \mathrm{~nm}$} \\
\hline Longyeab & 0.70 & 1.20 & 1.90 & 0.70 & 0.80 & 0.90 \\
\hline Greenland & 0.70 & 0.90 & - & 0.70 & 0.72 & - \\
\hline Antarctica & 0.65 & 0.90 & - & 0.65 & $\begin{array}{r}0.67 \\
\left(30^{\circ}\right)\end{array}$ & - \\
\hline \multicolumn{7}{|c|}{$670 / 440 \mathrm{~nm}$} \\
\hline Longyeab & 0.90 & 1.20 & 1.65 & 0.90 & 0.98 & 1.00 \\
\hline Greenland & 0.93 & 1.05 & - & 0.92 & 0.92 & - \\
\hline Antarctica & 0.91 & 1.06 & - & 0.90 & $\begin{array}{r}0.91 \\
\left(30^{\circ}\right)\end{array}$ & - \\
\hline
\end{tabular}

values $(\sim 0.7)$. The increase in the direction perpendicular to the Sun reaches 0.9 at $80^{\circ}$ view angle, but values are as high as 1.9 towards the Sun.

For a Lambertian surface, the reflectance does not depend on the view angle. In both observing directions we note that surface does not behave Lambertian, but for different reasons: towards the Sun, there is an additional broad specular component, which we can interpret as being caused by an orientation distribution of the flat snow crystals on ground with a broad maximum at flat orientation. A purely specular component would have a clear peak at the view angle of the Sun zenith angle, i.e. $72^{\circ}$, broadened by the orientation distribution of the snow crystals. However, the maximum reflectance has been observed at $80^{\circ}$ view angle. This discrepancy can hardly be explained with the sampling distance of $10^{\circ}$ view angle. Rather, it may be explained with the glint theory of Konoshonkin and Borovoi (2011) who showed that the width of the peak increases and the viewing zenith angle of the reflectance maximum decreases with the maximum tilt angle of the snow flakes.

In the direction perpendicular to the Sun, the increase of reflectance can be confirmed visually and qualitatively as explained by Fig. 6: the shadows of small-scale roughness in the snow become less visible at more oblique incidence angles.

The findings of Fig. 7 are qualitatively similar to those of Kokhanvosky and Breon (2011) taken from the satellite sensor PARASOL over snow in Greenland and Antarctica in the sense that they start with similar values at nadir observation and increase with view angle (Table 1). However, satellite and ground observations differ in two points. First, the maximum observed nadir view angle is in the satellite observations $60^{\circ}$ in direction towards sun and $50^{\circ}$ in the direction perpendicular to the Sun; in the Antarctic observations it is only $30^{\circ}$, whereas all Longyearbyen ground observations have been performed up to $80^{\circ}$ nadir view angle. Second, 

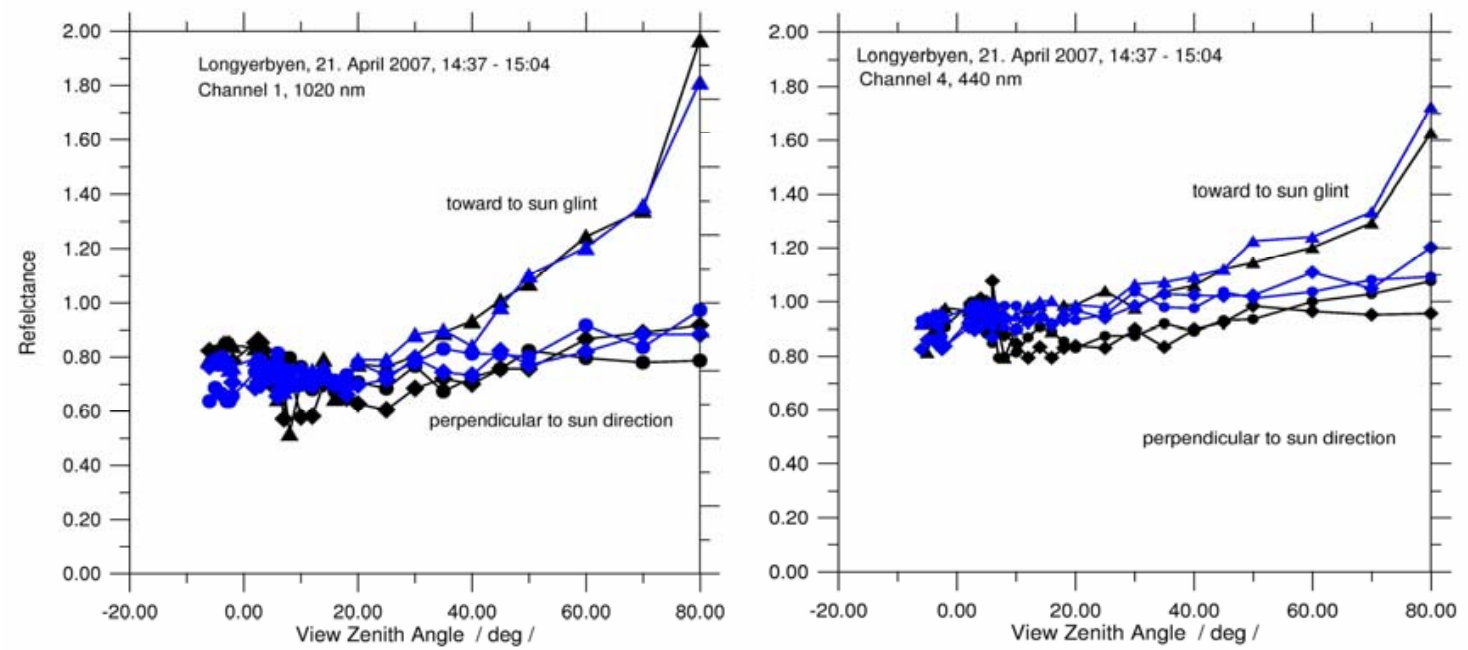

Fig. 7. Snow reflectance functions taken in Longyearbyen at $1020 \mathrm{~nm}$ (left) and $440 \mathrm{~nm}$ (right). Different curves represent different measurements.
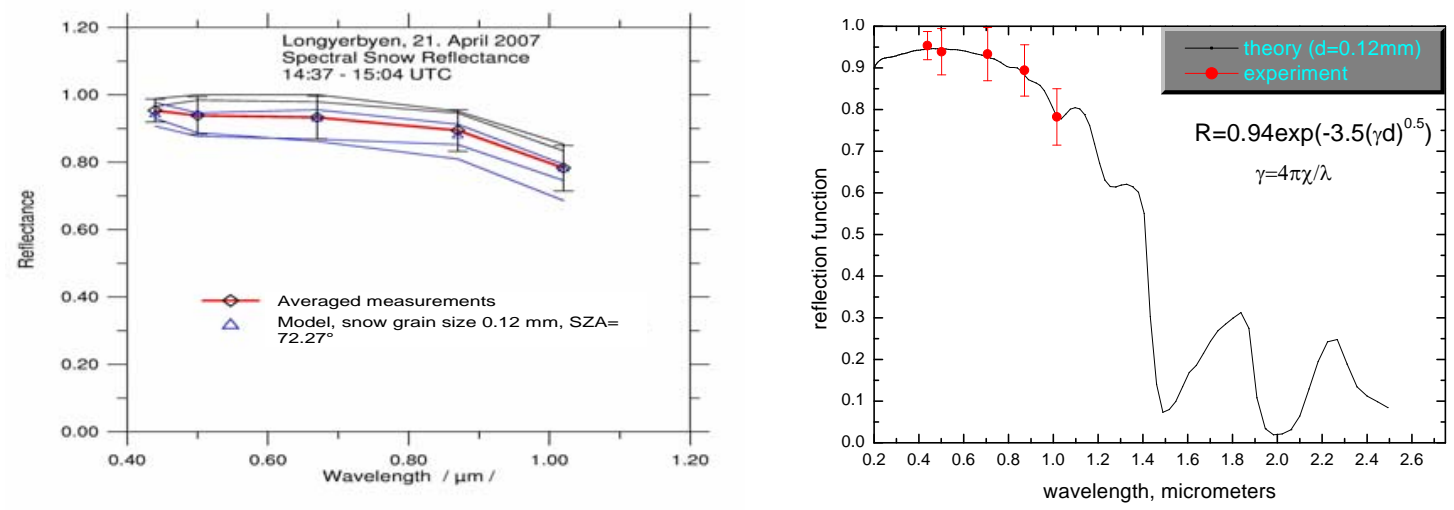

Fig. 8. (a) All observed reflectances, together with those obtained from the snow forward model of Kohanovsky et al. (2011) with effective grain size $0.12 \mathrm{~mm}$, (b) observed and modelled (Kohknaovsky et al., 2011) snow reflectance.

and perhaps more important, the increase of the reflectance with view angle is in all cases clearly more pronounced in the Longyearbyen observations, and the strong increase of the reflectance beyond $60^{\circ}$ in the direction toward the Sun is completely missed in the PARASOL observations. On the other hand, the PARASOL observations also cover negative view angles, i.e. in the direction pointing away from the Sun, which have not been taken in situ, so that both observations may complement each other when being used for modelling the snow reflectance.

The reflectances at the various wavelengths (Fig. 8a) can be used to determine the effective grain diameter that best fits the reflectance spectrum. This has been done using the forward model of Kokhanovsky et al. (2011), leading to an effective grain size of $0.122 \mathrm{~mm}$. The reflectances obtained from the forward model with this value are also shown in Fig. $8 \mathrm{a}$ and $\mathrm{b}$ and show the agreement of the calculated re- flectance function with the observations, at least in the wavelength range up to $1020 \mathrm{~nm}$.

\subsection{Snow albedo}

Currently the snow albedo is found using several satellite instruments. Routine visible satellite observations of the polar regions began in 1972 with launch of the first Landsat. The NOAA/AVHRR sensor provides the longest time series of surface albedo observations currently available. The AVHRR Polar Pathfinder (APP) (Fowler et al., 2000) product is available from the National Snow and Ice Data Center (http:/nsidc.org), providing twice daily observations of surface albedo for the Arctic and Antarctic from AVHRR spanning July 1981 to December 2000. The accuracy of this product is estimated to be approximately $6 \%$ (Stroeve et al., 2001). In addition, Riihelä et al. (2010) performed the validation of Climate-SAF surface broadband albedo using in 


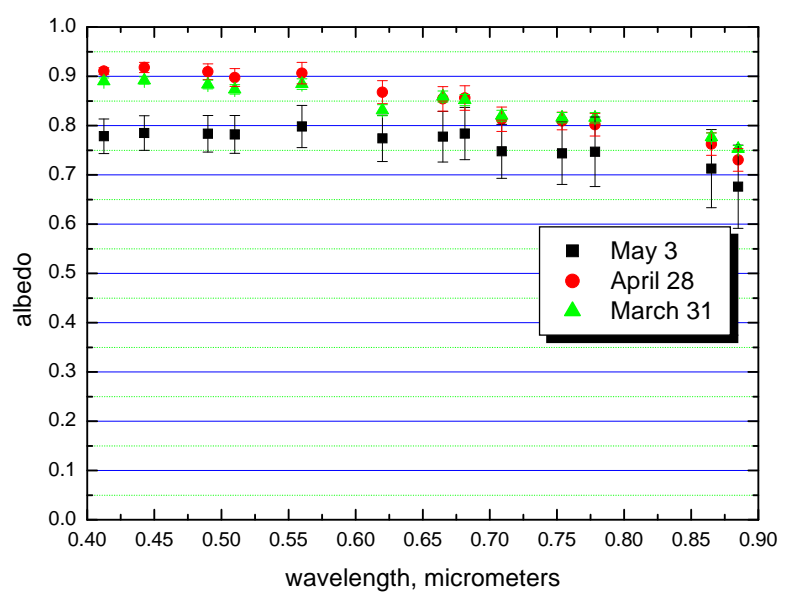

Fig. 9. The albedo retrieved from MERIS observations for several days in 2006 (average for all orbits). As it should be, albedo decreases with the wavelength and it is smaller for days with higher temperature. The results for the point with the coordinates $\left(24.6^{\circ} \mathrm{E}\right.$, $79.8^{\circ} \mathrm{N}$ ) are given (glacier Austfonna, island Nordaustlandet on Spitsbergen).

situ observations over Greenland and the ice-covered Arctic Ocean, and the seasonality of spectral albedo and transmissivity of sea ice were observed during the Arctic Transpolar Drift of the Schoner Tara in 2007 (Nicolaus et al., 2010). A prototype snow albedo algorithm for the MODIS instrument was developed by Klein and Stroeve (2002). Models of the bidirectional reflectance of snow created using a discrete ordinate radiative transfer (DISORT) model are used to correct for anisotropic scattering effects over non-forested surfaces. Maximum daily differences between the five MODIS broadband albedo retrievals and in situ albedo are $15 \%$. Daily differences between the "best" MODIS broadband estimate and the measured SURFRAD albedo are 1-8\%. Recently, Liang et al. (2005) developed an improved snow albedo retrieval algorithm. The most important improvement to the direct retrieval algorithm is that the nonparametric regression method (e.g. neural network) used in the previous studies has been replaced by an explicit multiple linear regression analysis. Another important improvement is that the Lambertian assumption used in the previous study has been replaced with a more explicit snow BRDF model. A key improvement is the inclusion of angular grids that represent reflectance over the entire Sun-viewing angular hemisphere. A linear regression equation is developed for each grid, and thus thousands of linear equations are developed in this algorithm for converting TOA reflectance to surface broadband albedo directly.

The shortcoming of methods described above is the use of an assumption that the snow grains have a spherical shape. Therefore, we have developed an approach that is based on the model of aspherical snow grains. In particular we have used the following equation for snow reflectance function $R$ (Zege et al., 1991):
$R=R_{0} A^{p}$

Here, $A$ is the snow albedo, $R_{0}$ is the snow reflection function for the nonabsorbing aspherical grains (precalculated values are assumed for fractal snow grains), $p=$ $K\left(\mu_{0}\right) K(\mu) / R_{0}, K(\mu)=\frac{3}{7}(1+2 \mu), \mu$ is the cosine of the observation zenith angle and $\mu_{0}$ is the cosine of the solar zenith angle. The atmospheric correction is applied to satellite data for the conversion of satellite - measured reflectance $R_{\text {sat }}$ to the value of snow reflectance $R$. Such an approach was validated using ground measurements (Negi and Kokhanovsky, 2010) and found to be a robust and fast method to derive snow albedo with account for the snow BRDF. We note that Eq. (1) can be used directly to find the snow albedo:

$A=\left(R / R_{0}\right)^{1 / p}$.

The results of retrievals for Spitzbergen are given in Fig. 9 . They are based on measurements of MERIS (MEdium Resolution Imaging Spectrometer) on board ENVISAT. Validation of the albedo retrievals can be done indirectly using the extensively validated grain size (Wiebe et al., 2012; Kokhanvosky et al., 2011).

\section{Sea ice drift and deformation}

The dynamic Arctic sea ice transports fresh water, its import contributes negatively to the latent heat budget, and it strongly influences the heat flux between ocean and atmosphere through opening and closing of the sea ice cover (Maykut, 1978; Marcq and Weiss, 2012). Sea ice dynamics also contribute to the ice thickness distribution through ridging and rafting. Thermodynamic ice growth leads to maximum thickness of about $3.5 \mathrm{~m}$ for multi-year ice (Eicken et al., 1995), higher thickness are typically generated by dynamic processes.

Within DAMOCLES, sea ice drift has been investigated with several sensors operating at different horizontal and temporal scales: with data from scatterometer (ASCAT) and passive microwave radiometers, both yielding drift fields at low resolutions of 50-100 km (Sects. 5.1 and 5.4), with data from the optical sensor AVHRR yielding medium resolution ice drift estimates (Sect. 5.2), and with Synthetic Aperture Radar data (ASAR) yielding a high resolution product (Sect. 5.3). For all products, different configurations of the Maximum Cross Correlation technique for pattern recognition (MCC) are used on consecutive satellite images for estimating the ice displacement. Different configurations of the technique are implemented to adapt to sensor characteristics such as spatial and temporal resolutions, the period of availability, the area of application, and the nature of the sensor. The central products characteristics are listed in Table 2. 
Table 2. Main characteristics of the ice drift data sets available from the Damocles project. Grid Spacing: spacing between ice motion vectors; Time Span: duration of the observed motion; Area Averaging: extent of the area of sea ice that is monitored by each motion vector; Data set Coverage: the period for which the data is available; Annual Coverage: the time of year in which ice drift data are produced.

\begin{tabular}{|c|c|c|c|c|c|c|c|}
\hline Product & $\begin{array}{l}\text { Source } \\
\text { Institution }\end{array}$ & $\begin{array}{l}\text { Instrument/ } \\
\text { Mode }\end{array}$ & $\begin{array}{l}\text { Grid } \\
\text { Spacing }\end{array}$ & $\begin{array}{l}\text { Time } \\
\text { Span }\end{array}$ & $\begin{array}{l}\text { Area } \\
\text { Averaging }\end{array}$ & $\begin{array}{l}\text { Data set } \\
\text { Coverage }\end{array}$ & $\begin{array}{l}\text { Annual } \\
\text { coverag }\end{array}$ \\
\hline OSI-405 & OSI SAF & $\begin{array}{l}\text { SSM/I, AMSR-E, } \\
\text { ASCAT }\end{array}$ & $62.5 \mathrm{~km}$ & $48 \mathrm{~h}$ & $\sim 140 \times 140 \mathrm{~km}^{2}$ & 2006-ongoing & Oct-May \\
\hline IFR-Merged & $\begin{array}{l}\text { CERSAT/ } \\
\text { IFREMER }\end{array}$ & $\begin{array}{l}\text { SSM/I, QuikSCAT, } \\
\text { ASCAT }\end{array}$ & $62.5 \mathrm{~km}$ & $72 \mathrm{~h}$ & $\sim 140 \times 140 \mathrm{~km}^{2}$ & 1992-ongoing & Oct-May \\
\hline IFR-89 GHz & $\begin{array}{l}\text { CERSAT/ } \\
\text { IFREMER }\end{array}$ & $\begin{array}{l}\text { AMSR-E } 89 \\
\text { GHz } H / V\end{array}$ & $31.25 \mathrm{~km}$ & $48 \mathrm{~h}$ & $\sim 70 \times 70 \mathrm{~km}^{2}$ & 2002-2011 & Oct-May \\
\hline OSI-407 & OSI SAF & AVHRR band $2 / 4$ & $20 \mathrm{~km}$ & $24 \mathrm{~h}$ & $\sim 40 \times 40 \mathrm{~km}^{2}$ & 2009-ongoing & All year \\
\hline DTU-WSM & DTU & ASAR-WSM & $10 \mathrm{~km}$ & $24 \mathrm{~h}$ & $\sim 10 \times 10 \mathrm{~km}^{2}$ & 2010-2012 & All year \\
\hline
\end{tabular}

All four ice drift products are developed jointly between the DAMOCLES project and other national and international projects.

Present ice drift products consist of sea ice displacement vectors over some period of time $(T$ to $T+d T)$ and for an area defined by the product grid size, the latter ranging between 10 and $100 \mathrm{~km}$ and dT ranging between $12 \mathrm{~h}$ and 3 days. The ice drift data contain no details of the sea ice during the displacement period, $d T$. Hence, a complete description of the sea ice dynamics requires high temporal and spatial resolution. However, a general condition of Earth observation data with satellites is that a tradeoff exists between temporal coverage and spatial resolution. Some data sets provide high temporal resolution; some provide very good spatial coverage whereas others provide only partial coverage of the Arctic. Some data sets are available only during winter months whereas others are available all year around. These are the reasons why it takes several different ice drift data sets to get detailed knowledge of sea ice dynamics on a broader range of spatial and temporal scales. Methods to relate data sets with different sampling characteristics have been suggested by, e.g. Rampal et al. (2008) from an analysis of drifting buoy dispersion. They found a power law relation between the temporal and spatial deformation.

Through the past decade drastic changes of the sea ice drift and deformation patterns in the Arctic Ocean have been reported in various studies (Vihma et al., 2012; Spreen et al., 2011; Rampal et al., 2009). These changes coincide with coherent reports on decreasing Arctic sea ice volume and general thinning of the ice cover (Kurtz et al., 2011; Kwok, 2011; Rothrock et al., 2008). The great loss of Arctic sea ice during the ice minimum in 2007 seem to have had a particular strong impact on the ice drift patterns, and especially the loss of large amounts of perennial sea ice in the Western Arctic seems to have changed the sea ice characteristics there (Maslanik et al., 2011). New results of drift and deformation characteristics in the Western Arctic are presented in Sect. 5.5. This analysis is based on ice drift and deformation data calculated from the full data set of AMSR-E passive microwave data from 2002 to 2011. These drift and deformation data constitute to our knowledge the most accurate and consistent daily and Arctic-wide data set covering this period.

\subsection{ASCAT and multi-sensor sea ice drift at IFREMER/Cersat}

Like SeaWinds/QuikSCAT, the scatterometer ASCAT is primarily designed for wind estimation over ocean. It is a Cband radar $(5.3 \mathrm{GHz})$ like two precursors on the European Research Satellites ERS-1 and ERS-2, respectively, henceforth together denoted as ERS. Like ERS, the ASCAT observing geometry is also based on fan-beam antennas. Over sea ice, the backscatter is related to the surface roughness of ice (at the scale of the wavelength used), which in turn is linked with ice age (Gohin, 1995). In contrast to open water, the backscatter is not a function of the azimuth of the beam but varies strongly with incidence angle. As a consequence, swaths signatures are clearly visible in ASCAT backscatter data, indicating that such data cannot be used directly for geophysical interpretation. It is indeed mandatory to construct incidence-adjusted ASCAT backscatter maps for sea ice application. It is noteworthy that the backscatter from SeaWinds/QuikSCAT scatterometer does not require an incidence angle correction because of its conically revolving antennas providing constant incidence angle. Based on the experience from ERS and NSCAT data, IFREMER has developed algorithms to compute incidence-adjusted backscatter maps normalized to $40^{\circ}$ incidence angle. Once corrected, the backscatter values over sea ice can be further interpreted with horizontally homogeneous retrieval algorithms in order to detect geophysical structures which can be compared to those from SeaWinds/QuikSCAT maps. ASCAT offers a complete daily coverage of the Arctic Ocean, although some peripheral regions are not entirely mapped each day (e.g. Baffin Bay).

One application of the ASCAT incidence-adjusted backscatter maps is to estimate sea ice displacement. Although single ice floes cannot be detected with the low pixel 
resolution available with microwave sensors such as ASCAT (typically 10-20 km), the general circulation of sea ice can effectively be mapped on a daily basis. Several motion extraction methods have been tested based on tracking common features in pairs of sequential satellite images. The most commonly used technique, the Maximum Cross Correlation (MCC), enables only detection of translation displacement (Kamachi, 1989; Ninnis et al., 1986). The main limitation of the MCC is the angular resolution for small drifts: the vector direction in slow motion areas has a larger uncertainty. A correlation is estimated between an array of the backscatter/brightness temperature map in one day and an array of the same size of another map separated in time. In particular, Girard-Ardhuin and Ezraty (2012) apply this process on the Laplacian field in order to enhance the structures to be tracked. The relative location of the maximum similarity between the arrays of the two original images is the displacement vector. To remove outliers, a threshold minimum correlation coefficient is imposed, and a comparison with the wind pattern is often applied (ECMWF model for Girard-Ardhuin and Ezraty, 2012; NCEP re-analyses for Kwok et al., 1998) since mean sea ice drift is strongly linked with geostrophic winds.

Brightness temperature maps from passive microwave radiometers have been used for sea ice drift estimation since the 1990s. The same method has been applied to scatterometer data, first with $12.5 \mathrm{~km}$ pixel resolution one day average SeaWinds/QuikSCAT backscatter maps and now with ASCAT (same grid resolution). This allows to process every day during winter, 3- and 6-day lag ice drift maps since 1992 with radiometers (SSM/I, AMSR-E) and scatterometers since 1999 with SeaWinds/QuikSCAT and ASCAT. The noise level is dominated by sensor ground resolution and pixel size. Advantages and shortcomings of each product depend on pixel sizes, period and magnitude of drift.

One recent major improvement of these drift estimations is the combination of two drift fields (QuikSCAT with SSMI and now ASCAT with SSMI): it provides better confidence in the results than each individually since each drift is inferred from independent measurements. The number of valid drift vectors is increased, in particular for early fall and early spring (more than 20\%), and the merged drift enables discrimination of outliers remaining in the individual products (Girard-Ardhuin and Ezraty, 2012). A time and space interpolation algorithm has been added to fill the gaps and provide the fullest field as possible, as often requested by the modelling community. The CERSAT/IFREMER backscatter and sea ice drift time series since 1992 is ongoing for Arctic long term monitoring with the Metop/ASCAT scatterometer data. Data are easy and free to access via the CERSAT portal (http://cersat.ifremer.fr). The merged sea ice drift products have been validated against buoys, and the standard deviation of the difference ranges from 6.2 to $8.6 \mathrm{~km}$, depending on the sensors and the day-lags used, including $5.1 \mathrm{~km}$ due to quantification effect (Girard-Ardhuin and Ezraty, 2012). Characteristic values of products are found in Table 2.

A recent study has made the effort to compare drift data sets at several resolutions from models, in situ and satellite observations in the particular area of the Laptev Sea, showing that the satellite-inferred drifts (those presented here and in Sect. 5.4) present good estimates; in particular the CERSAT/IFREMER product (Ifremer-89 GHz) has an especially strong correlation and low standard deviation compared to the reference data (Rozman et al., 2011).

\subsection{Sea ice drift from AVHRR observations}

For the DAMOCLES project, a MCC sea ice motion retrieval algorithm was developed for data from the Metop/AVHRR instrument. The setup operates on swath data at original spatial resolution (approximately $1 \mathrm{~km}$ ) of visible (VIS, channel 2) and Thermal InfraRed (TIR, channel 4) data. The VIS data are used during sunlit periods, when the TIR data show poor applicability for feature recognition as a consequence of low temperature difference between snow/ice interface and water. The TIR data are thus used during autumn, winter and spring, when leads, ridge zones and thin ice are easily recognised in the data. Characteristics of the setup are found in Table 2.

The use of satellite based VIS and TIR measurements for sea ice drift retrievals is limited by the presence of clouds, so the applicability is therefore constrained to areas below clear skies. This limitation, in combination with comprehensive filtering for dubious ice displacement vectors, causes large data gaps, especially during the Arctic summer when cloud cover prevails. However, the advantage of using AVHRR data for ice drift monitoring is the daily coverage of the Arctic region with high spatial resolution, providing high precision ice drift estimates. A comparison of this product to high precision GPS buoy positions shows that the standard deviation of the $24 \mathrm{~h}$ displacement error is around $1 \mathrm{~km}$ in both summer and winter (Hwang and Lavergne, 2010).

The AVHRR ice motion product is suited for data assimilation and for tuning of model ice parameters, like sea ice strength, thanks to its fine temporal and spatial resolution, as well as the high product accuracy. The product should also prove useful for validation of modelled sea ice motion. This $24 \mathrm{~h}$ ice motion product has subsequently been operationalized and is now available from the OSISAF web portal, where further documentation of the product is available (http://osisaf.met.no).

\subsection{Sea ice drift from ASAR observations}

Following the launch of the Radarsat-1 satellite in November 1995, ice drift and deformation applications such as the Radarsat Geophysical Processing System (RGPS) at the Alaskan SAR Facility (ASF) were developed. However, the Radarsat data were only available to the scientific community in very limited numbers, mainly due to the cost of the 


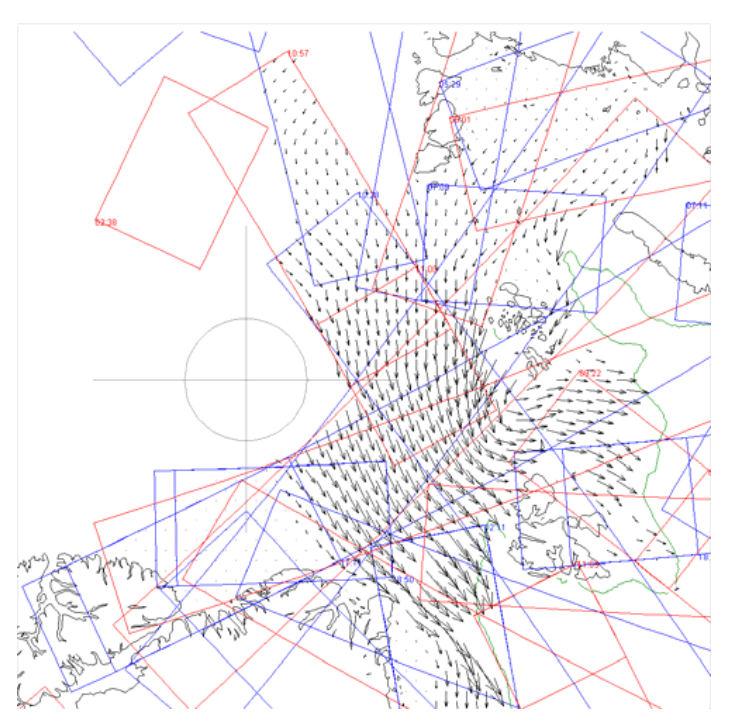

A:

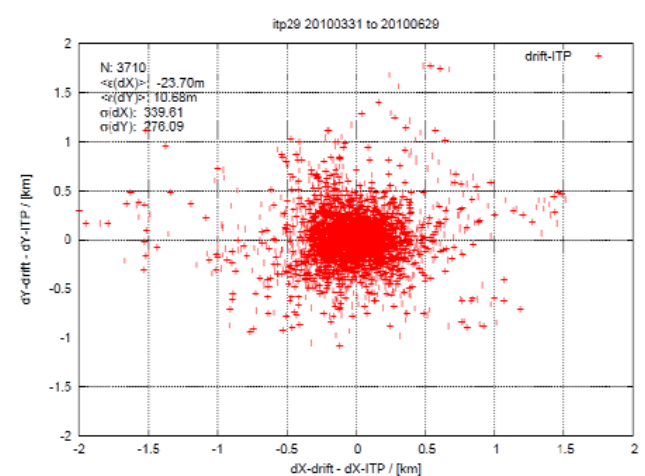

C:

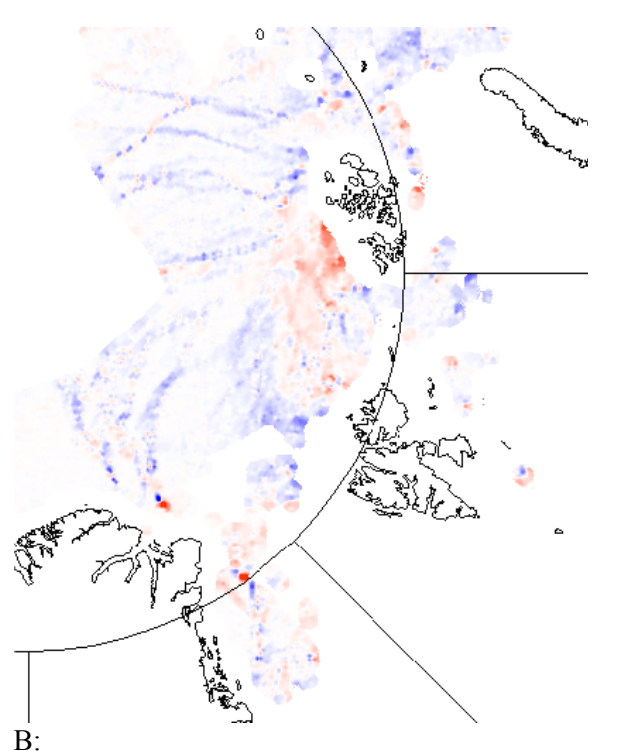

B:

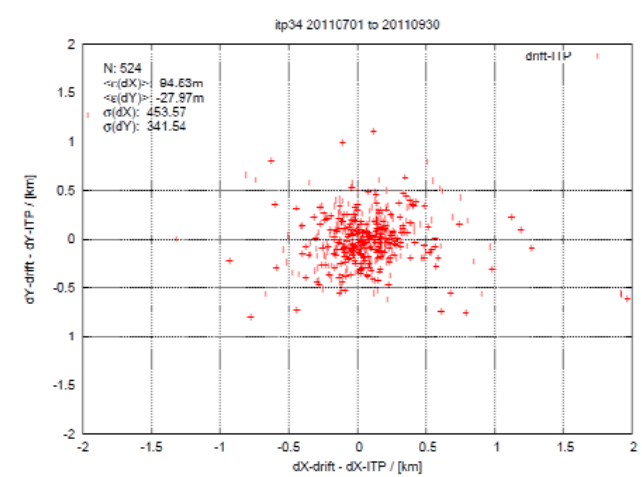

D:

Fig. 10. (A) Example of ice drift derived from ENVISAT ASAR WSM data between 15 March and 16 March 2010. Only every 25th vector shown. Red rectangles show ENVISAT WSM coverage on 15 March, blue on 16 March. (B) Example of corresponding ice deformation pattern derived by differentiating the ice drift field between 15 and 16 March 2010. Blue shows areas of divergence and red areas of convergence. (C) Validation of ice ENVISAT ASAR derived ice drift against hourly GPS locations from Ice Tethered Platforms (spring). Axes are difference in drift in $24 \mathrm{~h}$ (in km). (D) Validation of ice ENVISAT ASAR derived ice drift against hourly GPS locations from Ice Tethered Platforms (summer).

images. In 2002, ESA launched the Envisat satellite with its Advanced Synthetic Aperture Radar (ASAR) instrument, wherewith the data coverage increased tremendously. After the release of the coarse resolution $(1000 \mathrm{~m})$ Global Monitoring Mode (GMM) images in 2004, ice feature tracking from these images was developed at the Danish Technical University (DTU). The method is similar to the RGPS method, i.e. maximizing a two dimensional digital cross correlation (MCC) to find matches between images 3 days apart. Drift vectors every $20 \mathrm{~km}$ were derived, and the method proved skills in deriving ice drift even during the summer months where most other methods fail. In June 2007, ESA started providing much improved coverage of the polar regions, now in the finer resolution $(150 \mathrm{~m})$ Wide Swath Mode (WSM). Daily coverage of the European sector of the Arctic has been available almost continuously since 2007 . The DTU pro- cessing scheme was adapted to the higher resolution WSM scenes, and a data set of daily ice drift vectors from June 2007 to the present is being continuously updated, now as part of the EU MyOcean project. The individual $150 \mathrm{~m}$ resolution data-files are averaged and gridded to a polar stereographic projection at $300 \mathrm{~m}$ grid spacing, and ice features are tracked using circular subsets of $5 \mathrm{~km}$ radius sampled every $10 \mathrm{~km}$. Each swath of day 1 is correlated with each overlapping swath of day 2, which are separated in time by between 12 and $36 \mathrm{~h}$ (Table 2). The processing provides very accurate ice drift vectors from the coverage area (RMS difference to GPS buoys less than $500 \mathrm{~m}$ in $24 \mathrm{~h}$, see Fig. $10 \mathrm{c}$ and d). Mode detailed validation with GPS drift buoys show RMS uncertainties of between $200 \mathrm{~m}$ and $600 \mathrm{~m}$ for the $12-36 \mathrm{~h}$ drift vectors, depending somewhat on area and season (Hwang and Lavergne, 2010). This is substantially better than most other 
ice drift products. The coverage is generally limited to the area of the Arctic Ocean between $90^{\circ} \mathrm{W}$ and $90^{\circ} \mathrm{E}$ (see example in Fig. 10a). ENVISAT ASAR coverage only extends to approximately $87^{\circ} \mathrm{N}$. The ASAR ice drift data set can be derived all year round contrary to most other data sets (see Fig. 10d).

\subsection{Multi-sensor ice drift analysis at the EUMETSAT OSI SAF}

All ice drift products described previously in this chapter are based on the MCC algorithm. However, it exhibits strong weaknesses when the length of the displacement is short with respect to the pixel size. For example, displacements that are less than half an image pixel in length cannot be retrieved and are identified as zero-drift. For the same reason, the angular resolution of the motion vector field is poor for short displacement lengths. This noise is often referred to as the quantization noise or tracking error. While this does not restrict the usefulness for motion tracking from highresolution images (e.g. SAR, Sect. 3) or AVHRR (Sect. 5.2), the quantization noise is largely apparent in MCC-based motion vector fields from low-resolution images acquired by passive microwave instruments such as SSM/I, and AMSRE and scatterometers such as QuikSCAT/SeaWinds and ASCAT (Sect. 5.1).

An alternative motion tracking method was thus developed during the DAMOCLES project. The Continuous MCC (CMCC, Lavergne et al., 2010) is strongly linked to the MCC, but uses a continuous optimization step for finding the motion vector that maximizes the correlation metric. As a result, the quantization noise is removed, and the motion field obtained from the low-resolution images is spatially smooth and does not exhibit the MCC artefacts such as zero-length vectors and poor angular resolution. Particularly, the deformation metrics such as the convergence/divergence are more realistic from a field processed by the CMCC than by the MCC (see Sect. 5.5).

The CMCC was successfully applied to ice motion tracking from AMSR-E $(37 \mathrm{GHz}), \mathrm{SSM} / \mathrm{I}(85 \mathrm{GHz})$, and ASCAT daily images (12.5 km grid spacing). Validation against GPS buoys document un-biased and accurate estimates, with standard deviation of the error in $\mathrm{x}$ - and $\mathrm{y}$-displacement ranging from $2.5 \mathrm{~km}$ to $4.5 \mathrm{~km}$ after $48 \mathrm{~h}$ drift, depending on the instrument used. In any case, these validation statistics were documented to be better than those obtained from the same satellite sensors, even with using the more crude MCC technique (Sect. 4.3 in Lavergne et al., 2010).

The ice drift algorithms of Lavergne et al. (2010) were implemented in the operational processing chain of the EUMETSAT OSI SAF in late 2009. Daily products (OSI405 , both single- and multi-sensor, Table 2) are available from the OSI SAF web site (http://osisaf.met.no) for use in sea ice monitoring and data assimilation by coupled ocean and ice models (Lavergne and Eastwood, 2010).

\subsection{Sea ice deformation}

Sea ice drift and deformation generate leads, ridges and faulting in the sea ice cover with subsequent exposure of open water to the atmosphere, thus significantly increasing the transport of heat and humidity from the ocean to the atmosphere, as mentioned above. The ice drift speed and the degree of deformation depends on the main forcing parameters, wind and ocean current, and on the internal strength of the ice.

Thin ice deforms easier than thick ice (Kwok, 2006; Rampal et al., 2009; Stern and Lindsay, 2009). Ice deformation characteristics therefore function as a proxy for ice thickness and thus as an indicator of the state of sea ice, provided that wind and ocean forcing is even.

There are no simple and unambiguous trends in the surface wind patterns over the Arctic Ocean in recent years, and trends seem to depend on both season and region. Smedsrud et al. (2011) analyzed NCEP/NCAR reanalysis data and found that wind speeds have increased southward in the Fram Strait throughout the past $50 \mathrm{yr}$ and increasing the ice export here. Also using NCEP/NCAR reanalysis data, Hakkinen et al. (2008) report increasing storm activity over the central Arctic Ocean in the past $50 \mathrm{yr}$, resulting in positive trends of both wind stress and ice drift. Spreen et al. (2011) analyzed four different atmosphere reanalysis data sets for nearly two decades, up to 2009. Their analysis showed large regional differences, with areas of both negative and positive wind speed trends across the Arctic Ocean. However, both Vihma et al. (2012) and Spreen et al. (2011) found that the positive trends in sea ice drift during the past 2 decades cannot be explained by increased wind stress alone. This study shows no positive trends in wind speeds for the ice covered Arctic Ocean since 2002 (see Fig. 12).

More than $70 \%$ of the short term ice drift is explained by geostrophic wind (Thorndyke and Colony, 1982), thus leaving only a small fraction of the ice drift to surface current and internal stress. Therefore we assume that trends in the Arctic surface currents in the past decades have negligible influence on the changing characteristics of the Arctic sea ice dynamics. Rather we assume that the graduate thinning of the Arctic sea ice in recent years is the main cause for changing ice drift and deformation characteristics. This is also documented in several studies, e.g. Vihma et al. (2012), Spreen et al. (2011) and Rampal et al. (2009).

Several processes are responsible for the general thinning of the Arctic sea ice: increasing air temperatures resulting in fewer freezing degree days, increased export of MYI mainly through the Fram strait, and increased melt during summer, especially in the Beaufort Sea (BS) and Canadian Basin (CB). From maps of Arctic sea ice age distribution for May and September since 1983, it is evident that vast areas of old (thick) ice have been replaced by younger (thin) ice in recent years (Maslanik et al., 2011). The BS and CB that constitute a large part of the Western Arctic were previously covered with thick MYI all year round. This area has become an ice 


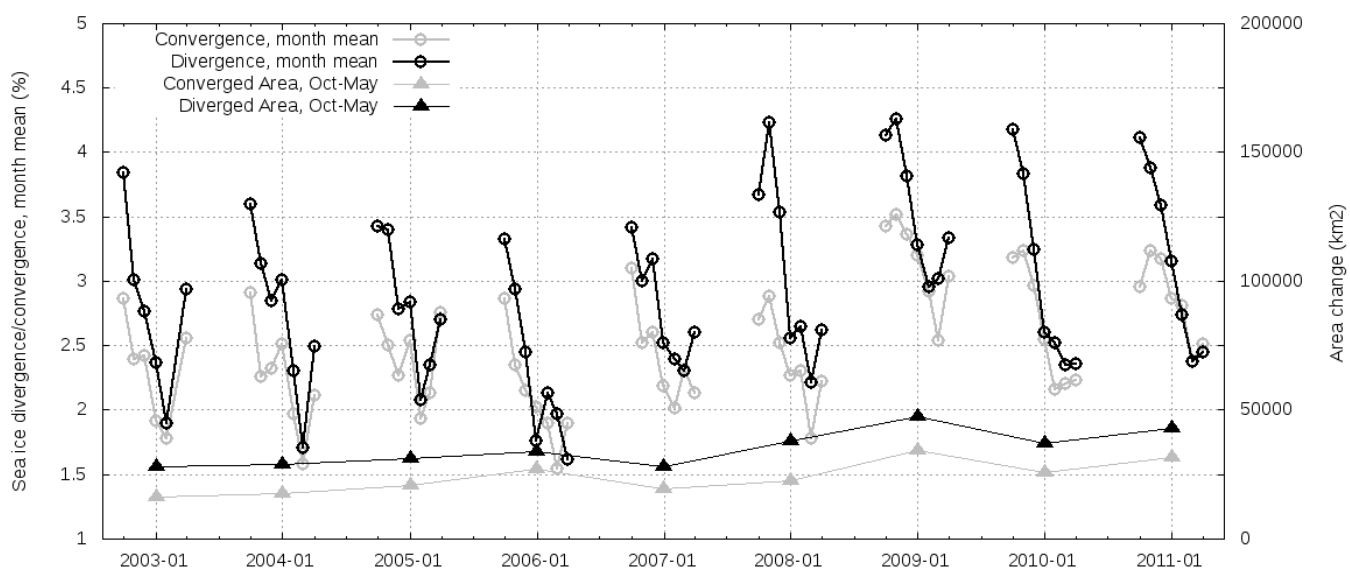

Fig. 11. Monthly mean values of Western Arctic $48 \mathrm{~h}$ sea ice divergence (black lines and circles) and convergence (grey lines and circles), during seven winter month (October-May) since 2002. Mean values are based on daily divergence fields calculated from AMSR-E ice drift fields using the CMCC algorithm. The ice convergence values are negative divergence values, but plotted here as absolute values for comparison to positive divergence values. The associated diverged and converged areas are plotted as aggregated winter (October-May) values in square kilometres (black and grey triangles, respectively).

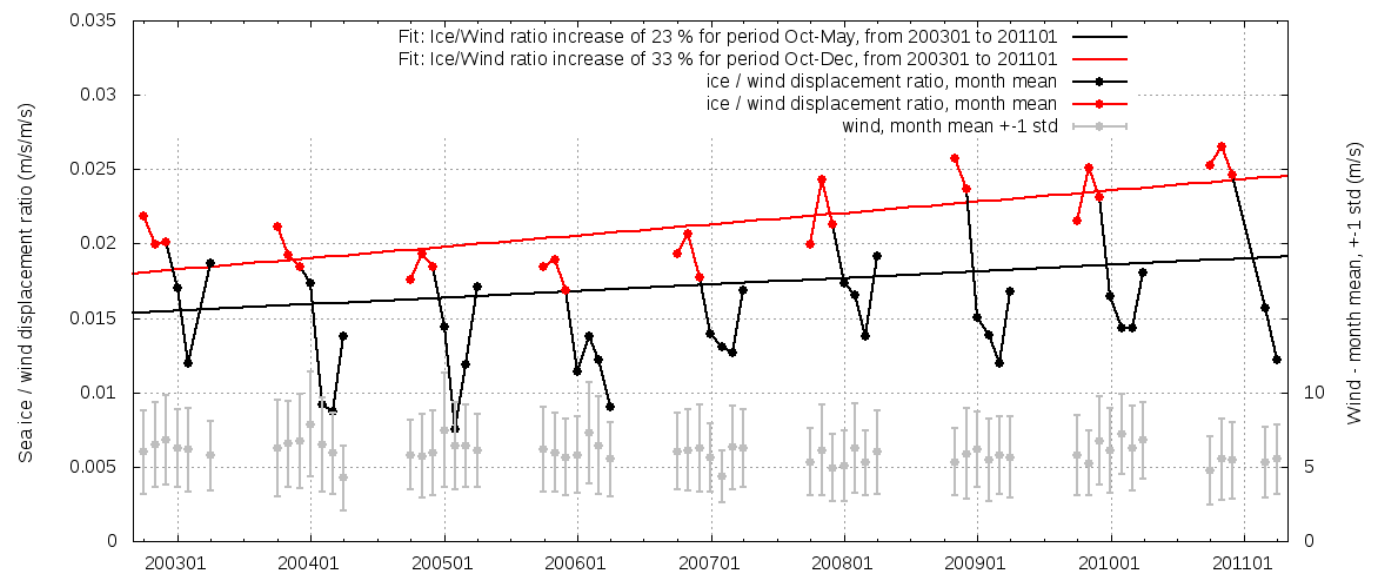

Fig. 12. Monthly mean ice/wind speed ratios, November 2002 to March 2012, from the Western Arctic regions. The red line is fitted to October-November-December data and the black line is the fitted line to all data (red and black), with levels of significance at 0.11 and 0.06 , respectively. The grey points with error bars are monthly mean wind speed with \pm 1 Standard deviation.

export and melt area during summer as the dominating anticyclonic rotation now exports MYI into the open water where it melts during summer. This is a very significant change in the sea ice of the Arctic Ocean in recent years. The ice drift and deformation results discussed below focus on the Western Arctic sea ice, as the largest changes are anticipated to emerge here.

An ice drift and deformation data set, based on the full time series of AMSR-E data (from 2002 to 2012), was analyzed for changing characteristics in the Western Arctic sea ice behaviour. The AMSR-E ice drift data set was produced using the CMCC methodology mentioned in Sect. 5.4. Ice divergence fields are produced from the highest quality and non interpolated drift vectors to ensure best quality data. The divergence is calculated as the area change of a grid cell (Dybkjaer, 2010). The uniqueness of this ice drift and divergence data set lies in the combination of high precision, daily Arctic coverage, high data consistency through the single sensor status and the fact that it covers the most dramatic changes in sea ice characteristics in recent years.

Sea ice divergence and convergence data for the Western Arctic Ocean are shown in Fig. 11 as mean monthly values. Mean divergence is estimated for all areas with a positive area change (opening of leads) and mean convergence is estimated for all areas with a negative area change (ridging and rafting) over $48 \mathrm{~h}$. An annually consistent feature in the data is the relative high deformation rates in the month after the summer melt period when large areas are covered by new 
and thin ice. The deformation rate is decreasing throughout the winter until spring where the deformation rate reaches its minimum and hereafter starts to increase. This is in qualitative agreement with the anticipated ice thickness development and its relation with deformation rates. The most conspicuous feature here is the shift of deformation level, after the winter of 2007/8. This is coherent with the replacement of vast areas of MYI with younger ice after the summer of 2007, as evident from the Arctic ice age distributions estimated by Maslanik et al. (2011). However, it is interesting that, for unidentified reasons, the convergence response to the 2007 event is delayed by $1 \mathrm{yr}$ whereas the divergence seems to react immediately to the 2007 ice extent minimum. After 2007, a new sea ice deformation regime has been established. These results reveal a clear response to changing ice age distribution (ice thickness), but a smooth trend indicating a gradual thinning of the Western Arctic sea ice is not evident in this data set. The absolute deformation areas are also plotted in Fig. 11, as aggregated October to May divergence and convergence areas. The absolute values must be treated with caution, as the deformation data set contains a coastal mask and also because possible smaller data gaps are not accounted for here. The deformation areas increase continuously throughout the data period, with a pronounced increase during the 2008 and 2009 winters. The increasing of deformed sea ice area is intuitively in line with increasing mean deformation values and thinning of the ice cover.

To look further into the ice response to a thinning ice cover, we analyzed the sea ice deformation response to the wind drag. This was done by matching deformation data with surface wind data from a NWP model.

In Fig. 12, monthly mean sea ice/wind speed ratios are plotted for the Western Arctic Ocean, i.e. longitudes from $0^{\circ} \mathrm{W}$ to $180^{\circ} \mathrm{W}$ and in Fram Strait cut off at $82^{\circ} \mathrm{N}$ area. Two lines are fitted to the data for estimating the ratio trends. The red line is the linear fit to October-November-December data (red points) and the black line is the linear fit to all the mean ice/wind speed ratios from October to May (red and black points). The grey points with the error bars are the corresponding mean monthly wind speed data plus/minus one standard deviation. The wind data are $10 \mathrm{~m}$ surface winds from the 00:00 UTC and 12:00 UTC analyses from the operational global deterministic model at ECMWF, at any given time, i.e. model data from 3 different surface resolutions are used in the matchup, namely T511 to February 2006, then T799 to January 2010, and T1279 till now, meaning spatial model resolutions of approximately 40,25 and $16 \mathrm{~km}$, respectively. All NWP data have been interpolated to a 0.5 degree grid.

Where the mean Arctic sea ice divergence data in Fig. 11 revealed no smooth trend following the general thinning of Arctic sea ice, changes in the sea ice/wind speed ratio show slightly increasing speed ratio over the past decade. This is seen in Fig. 12, showing trends in speed ratios of $23 \%$ and $33 \%$ and with significance levels 0.11 and 0.06 for October-December and October-May, respectively, from January 2003 to January 2011. The significance levels of the speed ratio increase of 11 and $6 \%$, respectively, mean that that there is 11 and $6 \%$ chance of accepting the Nullhypothesis, i.e. no trend, and inversely $89 \%$ and $94 \%$ chance of rejecting it. As these significances are near to the usual significance threshold of $5 \%$, but do not reach it completely, the trends should still be treated with caution, with the trend for October-December having a slightly higher significance. Note that the mean wind speeds seem relatively constant or even slightly lower in the past 3-4 yr, suggesting that the increase in drift speed is not related to an increase of wind forcing.

We found that the mean level of divergence and convergence shifted to a higher level after 2007 and the level seems to have stabilized at this new level. This alone does not imply a recovery of the Arctic sea ice since 2007, but it merely describes the state of sea ice deformation under the given atmospheric forcing. We estimate a positive trend in the ice/wind speed ratio of $33 \%$ for the period October-December and a positive trend of $23 \%$ for the cold season from October to May over the past 9 winters. This is in qualitative agreement with analysis of drifting buoy velocities in the Arctic Ocean, and both Vihma et al. (2012) and Hakkinen et al. (2008) found accelerating ice drift velocities throughout the past decades. Rampal et al. (2009) estimated the Arctic ice drift speed in the period December to May has increased by $17 \%$ per decade since 1979 . Provided no significant wind speed trends, this result is comparable to the ice/wind speed ratio trends found in this study and it thus supports the assumed acceleration of ice drift velocities in the Arctic Ocean. Furthermore, ice/surface-wind speed ratios of approximately $2.5 \%$ that we have observed since 2007 are very high and otherwise only observed for near free ice drift conditions (Kimura, 2004; Christoffersen, 2009) or when the ocean current is aligned with the ice drift. Rampal et al. (2011) have documented that the IPCC climate models do not reproduce the Arctic ice drift acceleration (Rampal et al., 2011).Therefore, the changes of the Arctic sea ice drift patterns is a critical issue for future IPCC Arctic Climate assessments.

\section{Sea ice thickness}

Satellite altimeter data can provide extensive spatial and temporal estimates of sea ice thickness through converting ice freeboard measurements to thickness by assuming hydrostatic equilibrium (Eq. 3):

$H_{\mathrm{i}}=\frac{\rho_{\mathrm{w}}}{\left(\rho_{\mathrm{w}}-\rho_{\mathrm{i}}\right)} F_{\mathrm{i}}+\frac{\rho_{\mathrm{sn}}}{\left(\rho_{\mathrm{w}}-\rho_{\mathrm{i}}\right)} H_{\mathrm{sn}}$,

where $H_{\mathrm{i}}$ is ice thickness; $F_{\mathrm{i}}$ is ice freeboard retrieved from radar-altimeter (RA) observations; $\rho_{\mathrm{w}}, \rho_{\mathrm{i}}$, and $\rho_{\mathrm{sn}}$ are water, sea ice, and snow densities, respectively; and $H_{\mathrm{sn}}$ is snow depth. Laxon et al. (2003) and Giles et al. (2008) converted 
the ice freeboard measurements to ice thickness in a basin wide scale using this approach with fixed values of seawater $\left(1023.9 \mathrm{~kg} \mathrm{~m}^{-3}\right)$ and ice $\left(915.1 \mathrm{~kg} \mathrm{~m}^{-3}\right)$ densities and a monthly climatology of snow depth and density from Warren et al. (1999). Analysis of ERS and Envisat RA data from 1992 to present has resulted in a unique data set on ice thickness south of $81.5^{\circ} \mathrm{N}$ (Giles et al., 2008). These ERS/Envisat sea ice thickness time series will be extended by CryoSat-2, which was launched in April 2010 and carries a RA that operates in a Synthetic Aperture Radar mode over sea ice, providing freeboard measurements with $250 \mathrm{~m}$ resolution along the satellite track (Wingham et al., 2006).

In this study we analyze available data on snow depth, ice, snow, and seawater densities in the Arctic. Snow depth on Arctic sea ice increases from a minimum in July-August to a maximum in April-May before the onset of summer melt (Warren et al., 1999). On multi-year ice in the Central Arctic the average snow depth is $0.35 \mathrm{~m}$ in May with an uncertainty of $0.06 \mathrm{~m}$ (Loshchilov, 1964; Warren et al., 1999). Several studies show that the mean snow depth is characterized with significant year-to-year and regional variations and also depends on ice type, i.e. it is substantially less on first-year ice as compared with multi-year ice (Yakovlev, 1960; Nazintsev, 1971; Buzuev et al., 1979; Romanov, 1995; Kwok et al., 2009). Romanov (1995) reports mean snow depth values of $0.05 \mathrm{~m}$ and $0.08 \mathrm{~m}$ for ice thicknesses in the ranges 0.30 to $1.60 \mathrm{~m}$ and 1.60 to $2.00 \mathrm{~m}$, respectively, and that the thinnest snow cover on first-year ice is found in the Canadian and Alaskan regions and the deepest in the Greenland region. According to Buzuev et al. (1979), snow depth on multi-year ice is $50 \%$ more than that on level first-year ice. Based on constructed daily fields of snow depth, Kwok et al. (2009) show that the mean snow depth over first-year ice amounts to 46 and $66 \%$ of that over multi-year ice in fall and winter, respectively. Nazintsev (1971) found that snow depth on level drifting floes in the Kara Sea varies from 0.05 to $0.13 \mathrm{~m}$ in spring, which is approximately three times less than that on fast ice. In the Fram Strait the average snow layer on both first-year and multi-year ice is $0.19 \mathrm{~m}$ thick in spring, and it varies greatly due to its redistribution by wind on an uneven surface. Snow depth in the Barents Sea is $0.13 \mathrm{~m}$ on average and it varies less (Forsstrom et al., 2011).

Analysis of publications shows that densities of snow on first-year and multi-year ice are not different. Nazintsev (1971) reports that snow density values in the Kara Sea are in the range of $300-340 \mathrm{~kg} \mathrm{~m}^{-3}$. The density of snow on multi-year ice in March-May amounts to $310-320 \mathrm{~kg} \mathrm{~m}^{-3}$ (Romanov, 1995; Warren et al., 1999), and is $340 \mathrm{~kg} \mathrm{~m}^{-3}$, according to measurements by Sturm et al. (2002). The presented data show that the mean snow depth and therefore snow load on multi-year ice exceeds that on first-year ice in most regions of the Arctic Ocean.

The most important factor determining the ice density in low temperatures is the fractional volume of air bubbles (Schwerdtfeger, 1963; Wadhams, 2000), which can reduce the density to $840 \mathrm{~kg} \mathrm{~m}^{-3}$ (Weeks, 1976). Generally there are lower values for multi-year ice compared to first-year ice above the waterline, which closely corresponds to the occurrence of air-filled pores in its freeboard layer. Densities of multi-year ice and first-year ice samples taken below the waterline are not significantly different. Timco and Frederking (1996) report that bulk density of first-year ice is typically between 840 and $910 \mathrm{~kg} \mathrm{~m}^{-3}$, while that of multi-year ice is between 720 and $910 \mathrm{~kg} \mathrm{~m}^{-3}$.

The main objective of our studies, conducted in the frames of the DAMOCLES project, consisted of studying the relation between ice freeboard and ice thickness using extensive in-situ sea ice measurements from the airborne Sever expeditions. The Sever expeditions provide one of the most extensive data sets of sea ice and snow parameters collected in 1928, 1937, 1941, 1948-1952, and 1954-1993. The measurements were conducted mostly from mid March to early May, when landing on ice floes was possible. The total data set, including 3771 landings, was obtained from the World Data Center for Glaciology/National Snow and Ice Data Center (NSIDC), Boulder, Colorado (National Snow and Ice Data Center, 2004). In this study data from 689 landings in 1980-1982, 1984-1986 and 1988, where freeboard measurements were included, have been analyzed. This subset spans the entire Eurasian Russian Arctic, where first-year ice is prevalent.

Data from the Sever expeditions show that in spring the median snow depth on level first-year ice is $0.05 \mathrm{~m}$ with the uncertainty of $0.05 \mathrm{~m}$. The average snow density on first-year ice, calculated from the Sever data, is $324 \pm 50 \mathrm{~kg} \mathrm{~m}^{-3}$. The difference in snow properties between multi-year and firstyear ice is therefore related to snow depth, not to snow density (Alexandrov et al., 2010).

The density of first-year ice was calculated for each of the 689 landings in Sever data by substituting $H_{\mathrm{i}}, F_{\mathrm{i}}$, and $H_{\mathrm{sn}}$ measurements, the mean calculated snow density $\left(324 \mathrm{~kg} \mathrm{~m}^{-3}\right)$, and water density value of $1025 \mathrm{~kg} \mathrm{~m}^{-3}$ to the Eq. (3) leading to:

$\rho_{\mathrm{i}}=\rho_{\mathrm{w}}-\frac{\rho_{\mathrm{w}} F_{\mathrm{i}}+\rho_{\mathrm{sn}} H_{\mathrm{sn}}}{H_{\mathrm{i}}}$

The mean ice density for first-year ice from the Sever data is $917 \pm 36 \mathrm{~kg} \mathrm{~m}^{-3}$ (Alexandrov et al., 2010).

In the analysis of ice thickness-freeboard relation the data from all landings were divided into two groups. The so-called runway data represent level ice, and the off-runway data can include ridges and various types of deformed and level ice, located around the level ice. The freeboard data were obtained only for level ice. The measurements show a linear increase in thickness vs. freeboard, and a linear regression equation between freeboard and average thickness is given by:

$H_{\mathrm{i}}=8.13 F_{\mathrm{i}}+0.37$ 
Equation (5) is applicable for level first-year ice in the Eurasian Arctic in the period March-May, but has to be modified for deformed first-year and multi-year ice (Alexandrov et al., 2010). However, taking into consideration that the snow climatology of Warren et al. (1999) is not valid for firstyear ice, ice thickness can be calculated during the whole winter, assuming that ice density and snow loading on the ice do not substantially change.

Thickness of multi-year ice can be calculated from the hydrostatic equilibrium equation with prescribed value of ice density and snow loading climatology from Warren et al. (1999). The major problem here is the correct estimate of multi-year ice density. Provision of improved ice density data is therefore necessary for accurate retrieval of ice thickness from CryoSat-2 data.

Using Sever data, the accuracy of the ice thickness retrieval has been calculated from the estimated variability in ice and snow parameters and error of ice freeboard measurements. The error in thickness retrieval is dominated by the freeboard error for thin first-year ice, while the effect of the ice density uncertainty increases as the freeboard increases. The ice density error prevails in thickness retrieval for multiyear ice. The error due to uncertainty in snow depth is smaller for both first-year and multi-year ice, and the influence of changes in snow and seawater densities is insignificant. For first-year ice, retrieval of $1.0 \mathrm{~m}(2.0 \mathrm{~m})$ thickness has an uncertainty of $46 \%$ (37\%), assuming that the freeboard error is $\pm 0.03 \mathrm{~m}$. If the freeboard error can be reduced to $0.01 \mathrm{~m}$ by averaging measurements from CryoSat-2, the error in thickness retrieval is reduced to about $32 \%$ for a $1.0 \mathrm{~m}$ thick firstyear floe. The remaining error is dominated by uncertainty in ice density (Alexandrov et al., 2010).

Obtained results may lead to further development of algorithms of ice thickness retrieval from RA data. Our studies revealed that different values of snow loading and density for first-year and multi-year ice should be used in ice thickness calculation from RA data. Areas of new/young, first-year, and multi-year ice can be delineated from weekly composite ice charts, issued by Arctic and Antarctic Research Institute (see Fig. 13 for an example from www.aari.nw.ru/main. $\mathrm{php}$ ?/g=0). Ice thickness in large areas of young ice can be derived using passive microwave radiometer data from Soil Moisture and Ocean Salinity (SMOS) satellite, which operate at $1.4 \mathrm{GHz}$ frequency (Kaleschke et al., 2010; Mills and Heygster, 2011).

The results obtained in the DAMOCLES project are based on measurements conducted in the Eurasian Arctic. Other studies, conducted in the area of the Fram Strait, revealed much larger contribution $(0.37 \mathrm{~m})$ of snow loading uncertainty in ice thickness retrieval (Forsstrom et al., 2011). Vinje and Finnekåasa (1986) and Forsstrom et al. (2011) derived empirical relations between ice thickness and freeboard in the Fram Strait and in the Barents Sea. Methods to estimate the snow depth on Arctic sea ice have been developed in several studies. Kwok and Cunningham (2008) produced daily fields of snow depth using available climatology and snowfall from ECMWF meteorological products and partitioned the total freeboard into its snow and ice components. Another possibility is to use AMSR-E snow depth averaged product (Comiso et al., 2003; Kurtz et al., 2009, Cavalieri et al., 2012). The accuracy of these snow depth estimates should be compared and validated.

\section{Conclusions}

In this review the main achievements of the DAMOCLES project in the field of remote sensing of sea ice have been presented. The backbone of sea ice remote sensing are passive microwave sensors like SSM/I, SSM/IS and AMSR-E. The radiance emitted by the surface is determined by the product of physical temperature and emissivity. The main limiting factor in sea ice retrieval is the uncertainty in the emissivity, which is much higher and much more variable compared to open water. In order to better understand the range of occurring values and their monthly change throughout the season, the sea ice emissivity for both a first-year and a multi-year ice region has been determined, including correlation values between the different channels (Figs. 1 and 2). Applying the results in the framework of an integrated retrieval of surface and atmospheric parameters shows that for a successful procedure it is necessary to better predict the emissivities, e.g. based on the meteorological history (Melsheimer et al., 2009).

As a first step towards this goal, in Sect. 2.1 the combination of a thermodynamic sea ice evolution model and a microwave emissivity model has been presented. Application of the model in the numerical weather prediction model HIRLAM shows that tropospheric temperature sounding over sea ice, currently not done operationally, is feasible.

Snow on sea ice acts as a thermal insulator and increases the albedo, which in turn is mainly controlled by the snow grain size (SGS). A method to retrieve the SGS has been developed, with the specific new features not to assume spherical snow crystals (as is usually done) and to work up to Sun incidence angles over $70^{\circ}$, a common condition in the polar regions (Figs. 4 and 5).

Moreover, a retrieval procedure for the spectral albedo without assuming spherical particles as usual before was established and applied to observations over Greenland (Fig. 9). The consequences of modifying accordingly atmospheric and ocean circulation models are investigated in a subsequent project.

Several methods based on Maximum Cross Correlation to retrieve the sea ice drift from the ENVISAT sensors ASAR, Metop sensors AVHRR and ASCAT, passive microwave sensors and sensor combinations have been improved. Typically the drift products have a lower horizontal resolution than the underlying sensor data (Table 2), but as digital derivatives they still tend to enhance noise present in the basic data. An 


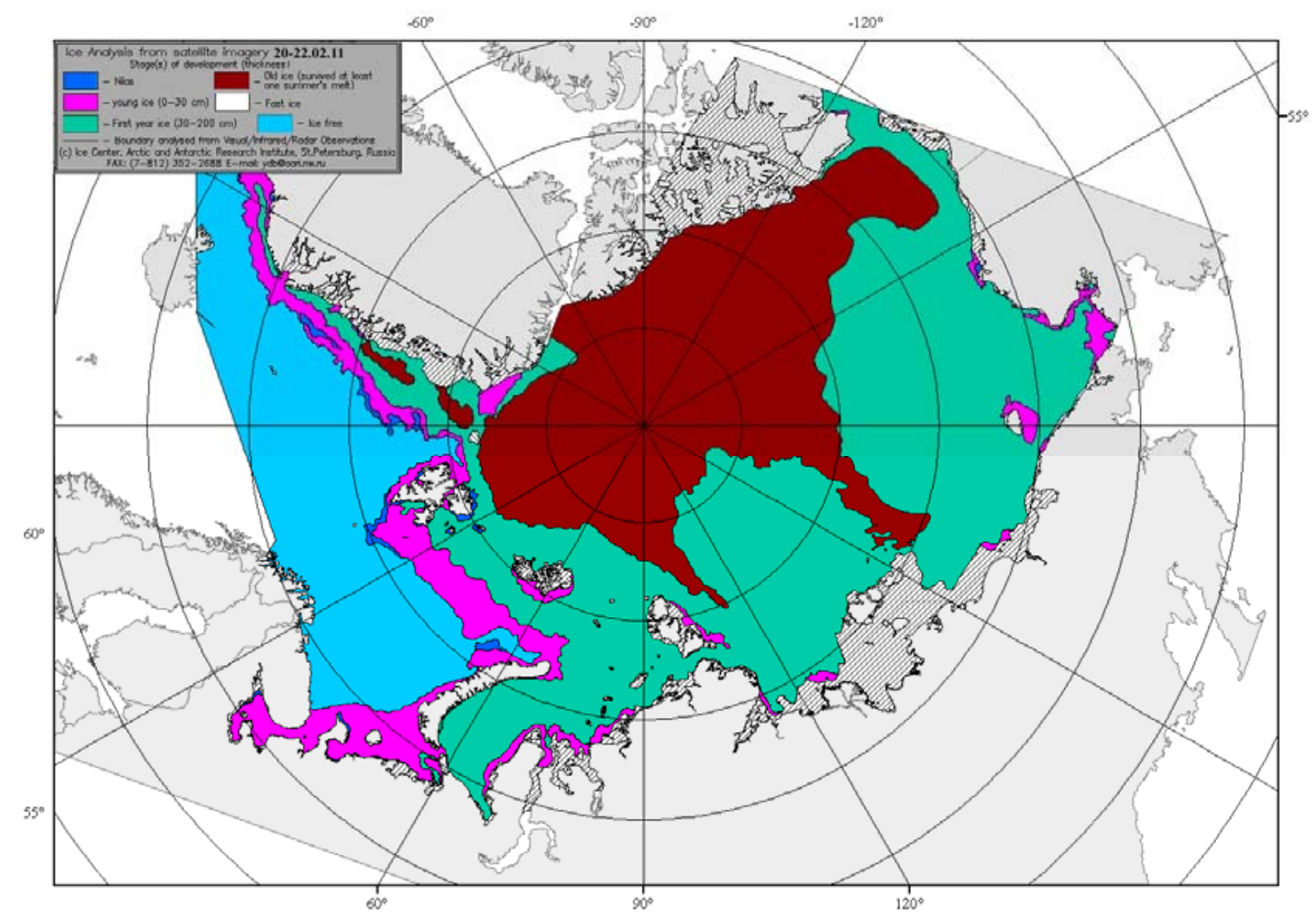

Fig. 13. The Arctic Ocean ice chart for the period 20-22 February 2011, issued by Arctic and Antarctic Research Institute.

improved Continuous Cross Correlation method, originally developed for the multi-sensor drift product, delivers drift fields smooth enough to determine the sea ice deformation (Sect. 5.5). The deformation fields, in terms of mean convergence and divergence and ice/wind displacement ratios, reveal large qualitative changes in the past decade, specifically in the West Arctic where both monthly sea ice divergence and convergence show a decrease with the year of the historic sea ice minimum 2007.

The data acquired within the DAMOCLES project, based on remote sensing as well as in situ observations and measurements, are accessible at http://damocles.met.no/data management/database.html. The meta-data can be browsed and searched and data can be downloaded in NetCDF format.

It is remarkable how the concerted effort of the scientific community during DAMOCLES to deploy, retrieve and share data from the ice surface directly benefited this validation work. Sea ice position data from the International Arctic Buoy Programme (IABP) and from drifting stations NP-35, NP-36, Tara, and 16 CALIB buoys deployed during the Tara expedition entered the study. The drift results were assimilated into the NAOSIMDAS model study and were used during the Sea Ice Outlook 2009 campaign. The ice drift produc- tion and further development are ensured through national projects and the Continuous Development and Operations Phases of EUMETSAT OSI SAF, where ice deformation is analysed for climate monitoring (Lavergne et al., 2010).

Large-scale remote sensing of sea ice thickness, done with freeboard observations from altimeters, is still a challenge. The analysis of the in-situ measurements of sea ice and snow parameters, collected in the airborne Sever expeditions between 1928 and 1993, has shown that currently the most important contributions to the thickness error are the uncertainties in ice density and measurements of freeboard. The error due to uncertainty in snow depth is smaller, and the influence of changes in snow and seawater densities is insignificant. If uncertainty of ice freeboard can be reduced for a typical first-year ice slab of $1 \mathrm{~m}$ thickness from 3 to $1 \mathrm{~cm}$, as we can expect from the CryoSat- 2 observations, the thickness error will reduce from 46 to $32 \%$. Our studies revealed that known parameters of snow load and ice density may serve to retrieve more accurately the thicknesses of first-year and multi-year ice from radar-altimeter data.

Not all important aspects of remote sensing of sea ice could be covered in detail in this collection. The time of the yearly onset of melt is an important parameter documenting the climate change particularly pronounced in the Arctic. 
The onset of melt primarily increases the water content of the snow on top of the ice. Ice and snow surfaces become wet, melt ponds appear, and the ice structure becomes more vulnerable to deformation by external forces so that leads appear. The strong changes of the microphysical properties create strong signals in macroscopic quantities like microwave emission and backscatter, as well as albedo which can be detected by satellite sensors. Within DAMOCLES, Maksimovich and Vihma (2012) have used the data set of Markus et al. (2009) based on passive microwave observation of SSM/I and SMMR, together with ECMWF ERA Interim reanalysis model data, to distinguish between the microphysical onset of snow melt on sea ice from the appearance of open water due to drift divergence. It turns out that the existing record of onset of melt seems to be a mixture of onset of snow melt and opening of leads and polynyas due to divergent ice drift.

Acknowledgements. The studies collected in this overview have been made possible by support through the EU FP 6 project DAMOCLES, and IPY (International Polar Year) project. A. Kokhanovsky thanks the German Ministry of Education and Technology for the support of his studies in the framework of CLIMSIP. The study also received financial support from the Danish Agency for Science, Technology and Innovation and is a part of the Greenland Climate Research Centre.

Edited by: K. Dethloff

\section{References}

Alexandrov, V., Sandven, S., Wahlin, J., and Johannessen, O. M.: The relation between sea ice thickness and freeboard in the Arctic, The Cryosphere, 4, 373-380, doi:10.5194/tc-4-373-2010, 2010.

Andersen, S., Tonboe, R., Kaleschke, L., and Heygster, G.: Intercomparison of passive microwave sea ice concentration retrievals over the high-concentration Arctic sea ice, J. Geophys. Res., 112, C08004, doi:10.1029/2006JC003543, 2007.

Aoki T., Hori, M., Motoyoshi, H., Tanikawa, T., Hachikubo, A., Sugiura, K., Yasunari, T. J., Storvold, R., Eide, H. A., Stamnes, K., Li, W., Nieke, J., Nakajima, Y., and Takahashi, F.: ADEOSII/GLI snow/ice products - Part 3: Validation results using GLI and MODIS data, Remote Sens. Environ., 111, 274-290, 2007.

Buzuev, A. Y., Romanov, I. P., and Fedyakov, V. E.: Variability of snow distribution on the ice in the Arctic Ocean, Meteorology and Hydrology, 9, 76-85, 1979.

Christoffersen, L. L.: The influence of wind on sea ice motion in the Baffin Bay, Master thesis in geophysics University of Copenhagen, April 12, 1-119, 2009.

Cavalieri, D. J., Gloersen, P., and Cambell, W. J.: Determination of sea ice parameters with the NIMBUS 7 SMMR, J. Geophys. Res. 89, 5355-5369, 1984.

Cavalieri, D. J., Markus, T., Ivanoff, A., Miller, J. A., Brucker, L., Sturm, M., Maslanik, J. A., Heinrichs, J. F., Gasiewski, A. J., Leuschen, C., Krabill, W., and Sonntag, J.: A comparison of snow depth on sea ice retrievals using airborne altimeters and an
AMSR-E simulator, IEEE T. Geosci. Remote, 50, 3027-3040, doi:10.1109/TGRS.2011.2180535, 2012.

Comiso, J. C., Cavalieri, D. J., Parkinson, C. L., and Gloersen, P.: Passive microwave algorithms for sea ice concentration: a comparison of two techniques, Remte Sens. Environ., 60, 357-384, 1997.

Comiso, J. C., Cavalieri, D. J., and Markus, T.: Sea ice concentration, ice temperature and snow depth using AMSR-E data, IEEE Transactions on Geoscience and Remote Sensing, Divergence, Wolfram Mathworld, 201005, http://mathworld.wolfram.com/Divergence.html, 41, 243-252, doi:10.1109/TGRS.2002.808307, 2003.

Dybkjaer, G.: Velocity and deformation fields from Medium and Low resolve - Passive Microwave and IR AVHRR data, DAMOCLES Deliverable Report D1.2-03d, 1-20, 2010.

Eicken, H., Lensu, M., Leppäranta, M., Tucker III, W. B., Gow, A. J., and Salmela, J. O.: Thickness, structure, and properties of level summer multiyear ice in the Eurasian sector of the Arctic Ocean, Geophys. Res., 100, 22697-22710, 1995.

Eppler, D. T., Farmer, L. D., Lohanick, A. W,. Andersson, M. R, Cavalieri, D. J., Comiso, J., Gloersen, P., Garrity, C., Grenfell, T. C., Hallikainen, M., Maslanik, J. A., Melloh, R. A., Runbinstein , I., Swift, C. T.: Passive Microwave Signatures of sea ice, in: Microwave Remote Sensing of Sea Ice, edited by: Carsey, F. D., AGU, Washington, DC, Geophys. Monogr. Ser., 68, 462 pp., doi:10.1029/GM068, 1992.

Forsstrom, S., Gerland, S., and Pedersen, C. A: Thickness and density of snow-covered sea ice and hydrostatic equilibrium assumption from in situ measurements in Fram Strait, Barents Sea and the Svalbard coast, Ann. Glaciol., 52, 261-270, 2011.

Fowler, C., Maslanik, J. , Haran, T., Scambos, T., Key, J., and Emery, W.: AVHRR Polar Pathfinder Twice-daily $5 \mathrm{~km}$ EASEGrid Composites V003, Boulder, Colorado, USA, National Snow and Ice Data Center, Digital media, 2007.

Gascard, J. C., Festy, J., le Gogg, H., Weber, M., Bruemmer, B., Offermann, M., Doble, M., Wadhams, P., Forsberg, R., Hanson, S., Skourup, H., Gerland, S., Nicolaus, M., Metaxin, J. P., Grangeon, J., Haapala, J., Rinne, E., Haas, C., Heygster, G., Jakobson, E., Palo, T., Wilkinson, J., Kaleschke, L., Claffey, K., Elder, B., and Bottenheim, J.: Exploring Arctic Transpolar Drift During Dramatic Sea Ice Retreat, EOS Trans., 89, 21-28, 2008.

Giles, K. A., Laxon, S. W., and Ridout, A. L.: Circumpolar thinning of Arctic sea ice following the 2007 record ice extent minimum, Geophys. Res. Lett., 35, L22502, doi:10.1029/2008GL035710, 2008.

Girard-Ardhuin, F. and Ezraty, R.: Enhanced Arctic sea ice drift estimateion merging radiometer and scatterometer data, IEEE Trans. Geosci. Remote Sens., 50, 2639-2648, doi:10.1109/TGRS.2012.2184124, 2012.

Gohin, F.: Some active and passive microwave signatures of Antarctic sea ice from mid-winter to spring 1991, Int. J. Remote Sens., 16, 2031-2054, 1995.

Haggerty, J. A. and Curry, H. A.: Variability of sea ice emissivity estimated from airborne passive microwave measurements during FIRE SHEBA, J. Geophys. Res., 106, 15265-15277, 2001.

Hakkinen, S., Proshutinski, A., and Ashik, I.: Sea ice drift in the Arctic since the 1950's, Geophys. Res. Lett., 35, L19704, doi:10.1029/2008GL034791, 2008. 
Han W., Stamnes, K., and Lubin, D.: Remote sensing of surface and cloud properties in the Arctic from NOAA AVHRR measurements, J. Appl. Meteor., 38, 989-1012, 1999.

Hansen, J. and Nazarenko, L.: Soot climate forcing via snow and ice albedos, Proc. Natl. Acad. Sci., 101, 423-428, doi:10.1073/pnas.2237157100, 2004.

Heygster, G., Melsheimer, C., Mathew, N., Toudal, L.,. Saldo, R, Andersen, S., Tonboe, R., Schyberg, H., Tveter, F. T., Thyness, V., Gustafsson, N., Landelius, T., Dahlgren, P., and Perov, V.: IOMASA - Integrated Observation and Modeling of the Arctic sea ice and atmosphere, Bull. Am. Met. Soc., 293-297, doi:10.1175/2008BAMS2202.1, 2009.

Hori, M., Aoki, T., Stamnes, K., Chen, B., and Li, W.: Preliminary validation of the GLI cryosphere algorithms with MODIS daytime data, Polar Meteorol. Glaciol., 15, 1-20, 2001.

Hwang, B. J. and Barber, D. G.: On the impact of ice emissivity on the sea ice temperature retrieval using passive microwave radiance data, IEEE Geosci. Remote Sens., 6, 448-452, 2008.

Hwang, P. and Lavergne, T.: Validation and Comparison of OSI SAF Low and Medium Resolution and IFREMER/Cersat Sea ice drift products, Associated and Visiting Scientist Activity Report, SAF/OSI/CDOP/met.no/SCI/RP/151 - Ocean and Sea Ice Satellite Application Facility, http://osisaf.met.no/docs/OSISAF_ IntercomparisonIceDriftProducts_V1p2.pdf, 2010.

Kaleschke, L., Maas, N., Haas, C., Hendricks, S., Heygster, G., and Tonboe, R. T.: A sea-ice thickness retrieval model for $1.4 \mathrm{GHz}$ radiometry and application to airborne measurements over low salinity sea-ice, The Cryosphere, 4, 583-592, doi:10.5194/tc-4583-2010, 2010.

Kamachi, M: Advective surface velocities derived from sequential images for rotational flow field: limitations and applications of Maximum Cross Correlation method with rotational registration, J. Geophys. Res., 94, 18227-18233, 1989.

Kimura, N.: Sea Ice Motion in Response to Surface Wind and Ocean Current in the Southern Ocean, J. Meteorol. Soc. Jpn., 82, 12231231, 2004.

Klein, A. G. and Stroeve, J.: Development and validation of a snow albedo algorithm for the MODIS instrument, Ann. Glaciol., 34, 45-52, 2002.

Kokhanovsky, A. A. and Breon, F.-M.: Validation of an Analytical Snow BRDF Model Using PARASOL Multi-Angular and Multispectral Observations, IEEE Geosci. Remote Sens. Lett., 9, 928932, 2012.

Kokhanovsky, V., Rozanov, V., Aoki, T., Odermatt, D., Brockmann, C., Krüger, O., Bouvet, M., Drusch, M., and Hori, M.: Sizing snow grains using backscattered solar light, Int. J. Remote Sens., 32, 6975-7008, 2011.

Konoshonkin, A. and Borovoi, A.: Glints from cirrus clouds, snow blankets, and sea surfaces, Atti della Accademia Peloritana dei Pericolanti, Supplement 1, 89, C1S8901XXX, 2011.

Kurtz, N. T., Markus, T., Cavalieri, D. J., Sparling, L. C., Krabill, W. B., Gasievski, A. J., and Sonntag, J. G.: Estimation of sea ice thickness distributions through the combination of snow depth and satellite laser altimeter data, J. Geophys. Res., 114 C10007, doi:10.1029/2009JC005292, 2009.

Kurtz, N. T., Markus, T., Farrell, S. L., Worthern, D. L., and Boisvert, L. N.: Observations of recent Arctic sea ice volume loss and its impact on ocean-atmosphere energy exchange and ice production, J. Geophys. Res., 116 C04015,
doi:10.1029/2010JC006235, 2011.

Kwok, R.: Contrasts in the sea ice deformation and production in the Arctic seasonal and perennial ice zones, J. Geophys. Res., 111, C11S22, doi:10.1029/2005JC003246, 2006.

Kwok, R.: Observational assessment of Arctic Ocean sea ice motion, export, and thickness in CMIP3 climate simulations, J. Geophys. Res., 116, C00D05, doi:10.1029/2011JC007004, 2011.

Kwok, R. and Cunningham, G. F.: ICESat over Arctic sea ice: Estimation of snow depth and ice thickness, J. Geophys. Res., 113, C08010, doi:10.1029/2008JC004753, 2008.

Kwok, R., Schweiger, A., Rothrock, D. A., Pang, S., and Kottmeier, C.: Sea ice motion from satellite passive microwave imagery assessed with ERS SAR and buoy motions, J. Geophys. Res., 103, 8191-8214, 1998.

Kwok, R., Cunningham, G. F., Wensnahan, M., Rigor, I., Zwally, H. J., and Yi, D.: Thinning and volume loss of the Arctic Ocean sea ice cover, 2003-2008, J. Geophys. Res., 114, C07005, doi:10.1029/2009JC005312, 2009.

Lavergne, T. and Eastwood, S.: Low resolution sea ice drift Product User's Manual - v1.4. Technical Report SAF/OSI/CDOP/met.no/TEC/MA/128, EUMETSAT OSI SAF Ocean and Sea Ice Satellite Application Facility, 29 pp., 2010.

Lavergne, T., Eastwood, S., Teffah, Z., Schyberg, H. and L.-A. Breivik, Sea ice motion from low resolution satellite sensors: an alternative method and its validation in the Arctic. J. Geophys. Res., 115, C10032, doi:10.1029/2009JC005958, 2010.

Laxon, S. W., Peacock, N., and Smith, D.: High interannual variability of sea ice thickness in the Arctic region, Nature, 425, 947949, 2003.

Liang, S.: Mapping daily snow/ice shortwave broadband albedo from Moderate Resolution Imaging Spectroradiometer (MODIS): The improved direct retrieval algorithm and validation with Greenland in situ measurements, J. Geophys. Res., 110, D10109, doi:10.1029/2004JD005493, 2005.

Loshchilov, V. S.: Snow cover on the ice of the central Arctic. Problemy Arktiki i Antarktiki, 17, 36-45, 1964.

Lüpkes, C., Vihma, T., Birnbaum, G., and Wacker, U.: Influence of leads in the sea ice on the temperature of the atmosphere boundary layer during polar night, Geophys. Res. Lett., 35, L03805, doi:10.1029/2007GL032461, 2008.

Marcq, S. and Weiss, J.: Influence of sea ice lead-width distribution on turbulent heat transfer between the ocean and the atmosphere, The Cryosphere, 6, 143-156, doi:10.5194/tc-6-143-2012, 2012.

Mätzler, C.: Improved Born approximation for scattering of radiation in a granular medium, J. Appl. Phys., 83, 6111-6117, 1998.

Mätzler, C. and Wiesmann, A.: Extension of the Microwave Emission Model for Layered Snow-packs to coarse grained snow, Remote Sens. Environ., 70, 317-325, 1999.

Mätzler, C., Rosenkranz, P. W., Battaglia, A., and Wigneron, J. P. (Eds.): Thermal Microwave Radiation - Applications for Remote Sensing, IEE Electromagnetic Wave Series, London, UK, 382400, 2006.

Maksimovich, E. and Vihma, T.: The effect of surface heat fluxes on interannualvariability in the spring onset of snow melt in the central Arctic Ocean, J. Geophys. Res., 117, C07012, doi:10.1029/2011JC007220, 2012.

Markus, T., Stroeve, J. C., and Miller, J.: Recent changes in Arctic sea ice melt onset, freeze up and melt season length, J. Geophys. Res., 114, C12024, doi:10.1029/2009JC005436, 2009. 
Maslanik, J., Stroeve J., Fowler, C., and Emory, W.: Distribution and trends in Arctic sea ice age through spring 2011, Geophys. Res. Lett., 38, L13502, doi:10.1029/2011GL047735, 2011.

Mathew, N., Heygster, G., Melsheimer, C., and Kaleschke, L.: Surface emissivity of polar regions at AMSU window frequencies, IEEE Trans. Geosci. Remote Sens., 46, 2298-2306, doi:10.1109/TGRS.2008.916630, 2008.

Mathew, N., Heygster, G., and Melsheimer, C.: Surface emissivity of the Arctic sea ice at AMSR-E frequencies, IEEE Trans. Geosci. Remote Sens., 47, 4115-4124, doi:10.1109/TGRS.2009.2023667, 2009.

Maykut, G. A.: Energy Exchange Over Young Sea Ice in the Central Arctic, J. Geophys. Res., 83, 3646-3658, doi:10.1029/JC083iC07p03646, 1978.

Maykut, G. A.: The surface heat and mass balance, in: The geophysics of sea ice, edited by: Untersteiner, N., NATO ASI Series, Plenum Press, New York and London, 395-464, 1986.

Melsheimer, C., Heygster, G., Mathew, N., and Toudal Pedersen, L.: Retrieval of Sea Ice Emissivity and Integrated Retrieval of Surface and Atmospheric Parameters over the Arctic from AMSR-E data, J. Remote Sens. Soc. Jpn., 29, 236-241, 2009.

Mills, P. and Heygster, G.: Sea ice emissivity modelling at Lband and application to Pol-Ice campaign field data, IEEE Trans. Geosci. Remote Sens., 49, 612-627, 2011.

National Snow and Ice data Center, Morphometric characteristics of ice and snow in the Arctic Basin: aircraft landing observations from the Former Soviet Union, 1928-1989, compiled by: Romanov, I. P., Boulder, CO, National Snow and Ice Data Center, Digital media, 2004.

Nagawo, M. and Sinha, N. K.: Growth rate and salinity profile of first year sea ice in the Arctic, J. Glaciol. 27, 315-330, 1981.

Nazintsev, Y. L.: About snow accumulation on sea ice of the Kara sea, Trudy Arkticheskogo 1 Antarknicheskogo Instituta, 303, 185-191, 1971.

Negi, H. S. and Kokhanovsky, A.: Retrieval of snow albedo and grain size using reflectance measurements in Himalayan basin, The Cryosphere, 5, 203-217, doi:10.5194/tc-5-203-2011, 2011.

Nicolaus, M. , Gerland, S. , Hudson, S. R., Hanson, S. , Haapala, J., and Perovich, D. K.: Seasonality of spectral albedo and transmissivity as observed in the Arctic Transpolar Drift in 2007, J. Geophys. Res.-Ocean, 115, C11011, doi:10.1029/2009JC006074, 2010.

Ninnis, R. M., Emery, W. J., and Collins, M. J.: Automated extraction of pack ice motion from Advanced Very High Resolution Radiometer imagery, J. Geophys. Res., 91, 10725-10734, 1986.

NSIDC: 201104, http://nsidc.org/arcticseaicenews/2011/040511. html, 2012.

Pirazzini, R.: Surface albedo measurements over Antarctic sites in summer, J. Geopys. Res., 109, D20118, doi:10.1029/2004JD004617, 2004.

Rampal, P., Weiss, J., Marsan, D., Lindsay, R., and Stern, H.: Scaling properties of sea ice deformation from buoy dispersion analysis, J. Geophys. Res., 113, C03002, doi:10.1029/2007JC004143, 2008.

Rampal, P., Weiss, J., and Marsan, D.: Positive trend in the mean speed and deformation rate of Arctic sea ice, 1979-2007, J. Geophys. Res., 114, C05013, doi:10.1029/2008JC005066, 2009.

Rampal, P., Weiss, J., Dubois, C., and Campin, J.-M.: IPCC climate models do not capture Arctic sea ice drift acceleration: 2
Consequences in terms of projected sea ice thinning and decline, J. Geophys. Res., 116, C00D07, doi:10.1029/2011JC007110, 2011.

Riihelä, A., Laine, V., Manninen, T., Palo, T., and Vihma, T.: Validation of the Climate-SAF surface broadband albedo product: comparisons with in situ observations over Greenland and the ice-covered Arctic Ocean, Remote Sensing of Environment, 114, 2779-2790, 2010.

Rodgers, C. D.: Inverse Methods for Atmospheric Sounding - Theory and Practise, Vol. 2 of Series on Atmospheric, Oceanic and Planetary Physics, World Scientific, ISBN 981-02-2740-X, 238 pp., 2000.

Romanov, I. P.: Atlas of ice and snow of the Arctic Basin and Siberian Shelf seas, Backbone Publishing Company, 496 pp. 1995.

Rothrock, D. A., Percival, D. B., and Wensnahan, M.: The decline in arctic sea-ice thickness: Separating the spatial, annual, and interannual variability in a quarter century of submarine data, J. Geophys. Res., 113, C05003, doi:10.1029/2007JC004252, 2008.

Rozman, P., Hölemann, J., Krumpen, T., Gerdes, R., Köberle, C., Lavergne, T., Adams, S., and Girard-Ardhuin, F.: Validating satellite derived and modeled sea ice drift in the Laptev sea with In Situ measurements of winter 2007/08, Polar Res., 30, doi:10.3402/polar.v30i0.7218, 2011.

Schwerdtfeger, P.: The thermal properties of sea ice, J. Glaciol., 4, 789-907, 1963.

Schyberg, H. and Tveter, F. T.: Report on microwave ice surface emission modelling using NWP model data, DAMOCLES deliverable report D1.2-02.f, 3, 11 pp., 2009.

Schyberg, H. and Tveter, F. T.: Improved assimilation method in NWP and impact on forecast quality in the Arctic, DAMOCLES deliverable report D4.3-09, 2010.

Seidel, K. and Martinec, J.: Remote Sensing in Snow Hydrology: Runoff Modelling, Effect of Climate Change, Chichester, Springer-Praxis, 150 pp., 2004.

Serreze, M. C., Barrett, A. P., Stroeve, J. C., Kindig, D. N., and Holland, M. M.: The emergence of surface-based Arctic amplification, The Cryosphere, 3, 11-19, doi:10.5194/tc-3-11-2009, 2009.

Smedsrud, L. H., Sirevaag, A., Kloster, K., Sorteberg, A., and Sandven, S.: Recent wind driven high sea ice area export in the Fram Strait contributes to Arctic sea ice decline, The Cryosphere, 5, 821-829, doi:10.5194/tc-5-821-2011, 2011.

Spreen, G., Kaleschke, L., and Heygster, G.: Sea ice remote sensing using AMSR-E $89 \mathrm{GHz}$ channels, J. Geophys. Res., 113, C02S03, doi:10.1029/2005JC003384, 2008.

Spreen, G., Kwok, R., and Menemenlis, D.: Trends in Arctic sea ice drift and role of wind forcing, 1992-2009, Geophys. Res. Lett., 38, L19501, doi:10.1029/2011GL048970, 2011.

Stamnes, K., Li, W., Eide, H., Aoki, T., Hori, M., and Storvold, R.: ADEOS-II/GLI Snow/Ice Products - Part 1: Scientific Basis, Remote Sensing of the Cryosphere, Special Issue 111, 2-3, 2007.

Stern, H. L., and Lindsay, R. W.: Spatial scaling of Arctic sea ice deformation, J. Geophys. Res., 114, C10017, doi:10.1029/2009JC005380, 2009.

Stroeve, J., Box, J., Fowler, C., Haran, T., and Key, J.: Intercomparison between in situ and AVHRR Polar Pathfinder-derived Surface Albedo over Greenland, Remte Sens. Environ., 75, 360-374, 2001. 
Sturm, M., Holmgren, J., and Perovich, D. K. : Winter snow cover on the sea ice of the Arctic Ocean (SHEBA): Temporal evolution and spatial variability, J. Geophys. Res., 107, 8047, doi:10.1029/2000JC000400, 2002.

Thorndyke, A. S. and Colony, R.: Sea ice motion in response to geostrophic winds, J. Gephys. Res., 87, 5845-5852, 1982.

Timco, G. W., and Frederking, R. M. W.: A review of sea ice density, Cold Reg. Sci. Technol., 24, 1-6, 1996.

Tonboe, R.: The simulated sea ice thermal microwave emission at window and sounding frequencies, Tellus, 62, 333-344, doi:10.1111/j.1600-0870.2010.00434.x, 2010.

Tonboe, R. T. and Schyberg, H.: Algorithm theoretical basis document for the OSI SAF $50 \mathrm{GHz}$ sea ice emissivity model. OSI404, EUMETSAT OSI SAF report, 22, 28 pp., 2011.

Tonboe, R., Andersen, S., Toudal, L. and Heygster, G.: Sea ice emission modelling, in: Thermal Microwave Radiation - Applications for Remote Sensing, edited by: Mätzler, C., Rosenkranz, P. W., Battaglia, A., and Wigneron, J. P., IET Electromagnetic Waves Series 52, London, UK, 382-400, 2006.

Tonboe, R. T., Dybkjær, G., and Høyer, J. L.: Simulations of the snow covered sea ice surface temperature and microwave effective temperature, Tellus A, 63, 1028-1037, 2011.

Tynes, H., Kattawar, G. W., Zege, E. P., Katsev, I. L., Prikhach, A. S., and Chaikovskaya, L. I.: Monte Carlo and multi-component approximation methods for vector radiative transfer by use of effective Mueller matrix calculations, Appl. Opt., 40, 400-412, 2001.

Ulaby, F. T., Moore, R. K., and Fung, A. K.: Microwave remote sensing, Active an passive, From Theory to Applications, Artech House, Norwood, MA, USA, 3, 2162 pp., 1986.

Vinje, T. and Finnekåasa, Ø.: The ice transport through the Fram Strait, Skrifter Nr. 186, Norsk Polarinstitutt, 39 pp., 1986.

Vihma, T., Tisler, P., and Uotila, P.: Atmospheric forcing on the drift of Arctic sea ice in 1989-2009, Geophys. Res. Lett., 39, L02501, doi:10.1029/2011GL050118, 2012.

Wadhams, P.: Ice in the Ocean, Gordon and Breach Science Publishers, Amsterdam, 351 pp., 2000.
Warren, S. G., Rigor, I. G., Untersteiner, N., Radionov, V. F., Bryazgin, N. N., Aleksandrov, Y. I., and Colony, R.: Snow depth on Arctic Sea Ice, J. Climate, 12, 1814-1829, 1999.

Weeks, W. F.: Sea ice properties and geometry, AIDJEX Bulletin 34, 137-172, 1976.

Wentz, F. J.: Model function for ocean microwave brightness temperatures, J. Geophys. Res., 88, 1892-1908, 1983.

Wentz, F. J. and Meissner, T.: AMSR Ocean Algorithm, Algorithm Theoretical Basis Document (ATBD), Version 2, Remote Sensing Systems, California, US, 55 pp., 2000.

Wiebe, H., Heygster, G., Zege, E., Aoki, T., and Hori, M.: Snow grain size retrieval SGSP from optical satellite data: Validation with ground measurements and detection of snowfall events, Remote Sens. Environ., 128, 11-20, 2012.

Wiesmann, A. and Mätzler, C.: Microwave emission model of layered snowpacks, Remote Sens. Environ., 70, 307-316, 1999.

Wingham, D. J., Francis, C. R., Baker, S., Bouzinac, C., Brockley, D., Cullen, R., de Chateau-Thierry, P., Laxon, S. W., Mallow, U., Mavrocordatos, C., Phalippou, L., Ratier, G., Rey, L., Rostan, F., Viau, P., and Wallis, D. W.: CryoSat: A mission to determine the fluctuations in Earth's land and marine ice fields, Advances in Space Research, 37, 841-871, doi:10.1016/j.asr.2005.07.027, 2006.

Yakovlev, G. N.: Snow cover on drifting ice in the central Arctic, Problemy Arktiki I Antarktiki, 3, 65-76, 1960.

Zege, E. P., Ivanov, A. P., and Katsev, I. L.: Image Transfer through a Scattering Medium, Springer-Verlag, Heidelberg, 139-144, 1991.

Zege, E., Katsev, I., Malinka, A., Prikhach, A., and Polonsky, I.: New algorithm to retrieve the effective snow grain size and pollution amount from satellite data, Ann. Glaciol., 49, 139-144, 2008.

Zege, E. P., Katsev, I. L., Malinka, A. V., Prikhach, A. S., Heygster, G., and Wiebe, H.: Algorithm of the effective snow grain size and pollution amount retrieval from satellite data, Remote Sens. Environ., 115, 2674-2685, 2011. 